\title{
The interplay of early-life stress, nutrition, and immune activation programs adult hippocampal structure and function
}

\author{
Lianne Hoeijmakers, Paul J. Lucassen and Aniko Korosi* \\ Center for Neuroscience, Swammerdam Institute for Life Sciences, University of Amsterdam, Amsterdam, Netherlands
}

\section{Edited by:}

Mathias V. Schmidt, Max Planck

Institute of Psychiatry, Germany

\section{Reviewed by:}

David A. Slattery, University of

Regensburg, Germany

Sarah J. Spencer, RMIT University,

Australia

\section{*Correspondence:}

Aniko Korosi, Center for Neuroscience, Swammerdam Institute for Life Sciences, University of Amsterdam, Science Park 904, Amsterdam, Netherlands e-mail:a.korosi@uva.n
Early-life adversity increases the vulnerability to develop psychopathologies and cognitive decline later in life. This association is supported by clinical and preclinical studies. Remarkably, experiences of stress during this sensitive period, in the form of abuse or neglect but also early malnutrition or an early immune challenge elicit very similar long-term effects on brain structure and function. During early-life, both exogenous factors like nutrition and maternal care, as well as endogenous modulators, including stress hormones and mediator of immunological activity affect brain development. The interplay of these key elements and their underlying molecular mechanisms are not fully understood. We discuss here the hypothesis that exposure to early-life adversity (specifically stress, under/malnutrition and infection) leads to life-long alterations in hippocampal-related cognitive functions, at least partly via changes in hippocampal neurogenesis. We further discuss how these different key elements of the early-life environment interact and affect one another and suggest that it is a synergistic action of these elements that shapes cognition throughout life. Finally, we consider different intervention studies aiming to prevent these early-life adversity induced consequences. The emerging evidence for the intriguing interplay of stress, nutrition, and immune activity in the early-life programming calls for a more in depth understanding of the interaction of these elements and the underlying mechanisms. This knowledge will help to develop intervention strategies that will converge on a more complete set of changes induced by early-life adversity.

Keywords: hippocampus, neurogenesis, cognition, early-life stress, early-life nutrition, early-life neuroimmune activation, early-life infection

\section{INTRODUCTION}

Clinical studies have provided evidence that cognition in later life is strongly influenced by experiences occurring during the sensitive period of early development and adolescence. Indeed, adverse early-life events, e.g., social deprivation or abuse, are associated with an increased vulnerability to develop psychiatric disorders (Stevens et al., 2008; Maselko etal., 2011) and impaired cognitive functioning in adulthood (Chugani et al., 2001; Kaplan et al., 2001; Nelson et al., 2007; Mueller et al., 2010). Interestingly, exposure to prenatal or postnatal malnutrition, e.g., the lack of one or multiple essential nutrients, can lead to a similarly increased incidence of psychopathologies (Brown et al., 2000; Costello et al., 2007; Mueller et al., 2010) and cognitive deficits in adolescence and adulthood (Walker et al., 2000; Benton, 2010; de Rooij et al., 2010; de Groot etal., 2011; de Souza etal., 2011; Laus et al., 2011).

Different lines of work further illustrate the relation between cognitive functions and postnatal immune system activity. For example, maternal inflammatory responses during pregnancy (Eriksen etal., 2009), antenatal infection in preterm babies (Dammann et al., 2002; Eriksen etal., 2009; van der Ree et al., 2011) and neonatal infection (Rantakallio et al., 1997; Libbey et al., 2005) are suggested as risk factors for a lower IQ later in life and for an increased vulnerability to develop later neuropsychiatric disorders like schizophrenia and depression (Brown, 2006; Cope and Gould, 2013; Miller et al., 2013; O'Connor et al., 2014). These lines of research support the hypothesis postulated in the developmental origins theory of Barker that the early-life environment determines the framework for later adult functioning and the development of pathologies through an early programming of adult brain structure and function (Barker, 2004; Barker et al., 2013). Although the consequences of an adverse early-life history for adult cognitive function are confirmed by evidence from preclinical studies in rodents (Lucassen et al., 2013; Naninck et al., 2013), the exact mechanisms underlying these programming effects and the determining elements in the environment that modulate these processes remain obscure. As is clear from the above examples, early-life environmental experiences cannot be avoided (Danese et al., 2009; Bale et al., 2010) and it is thus crucial to understand which elements play a role, and how they interact in order to develop future interventions.

The early postnatal environment encompasses many essential elements, which are key and determinant for proper brain development, many of which are largely transmitted via the mother-child interaction. A child is generally dependent on maternal care during the first weeks of life, encompassing tactile stimulation, 
nutritional provision, as well as transfer of antibodies and maternal warmth. As is evident from the above examples, an adverse early-life environment may affect the stress hormones, nutrition, or inflammatory modulators, all elements that can strongly interact and affect one another (Kelly and Coutts, 2000; Shanks and Lightman, 2001; Miller et al., 2009; Palmer, 2011). Hence, an individual is actually exposed to a combination of these factors rather than to one of these elements independently.

There is, e.g., increasing evidence that early-life maltreatment is associated with an increase in the pro-inflammatory markers of the immune system in adulthood (Coelho et al., 2014). Also, associations have been found between maternal supplementation of specific nutrients (e.g., folate, iodine, and vitamin D) and an enhanced fetal immune system development that was paralleled by a reduced incidence of psychopathologies in adulthood (Marques et al., 2013). Also, Monk et al. (2013) reviewed the interrelation of nutrition and prenatal stress in stress-induced maternal malnutrition. An interrelated profile of different early-life elements brings forward the possibility of confounding factors in the currently reported findings on the possible mechanisms that underlie such programming. Interestingly, most studies addressing the mechanisms underlying early-life programming consider these elements individually, but, considering that each one of these elements has a very strong interaction with one another, and influence each other greatly, it is likely that the final effect will be determined by the synergistic action of the different early-life elements at play. Hence, it will be necessary to re-discuss and re-analyze the so far obtained results in light of such interactions.

The focus of this review will be on the essential elements present in the early postnatal environment and their involvement in the lasting effects on cognitive functioning. In particular we will discuss how the various elements during the early postnatal period (i.e., sensory stimuli, nutrition, stress hormones, and inflammatory molecules) interact, affect each other and ultimately how they may synergistically affect brain structure, and function on the long term. We focus on the consequences for hippocampal structure and related cognitive functioning and on a unique form of hippocampal plasticity, adult neurogenesis. The hippocampus is one of the key brain regions important for cognitive functions and this form of plasticity is very important for learning and memory processes and highly modulated by (early) environmental factors, i.e., stress (Gould et al., 2000; Mirescu et al., 2004; Dranovsky and Hen, 2006; Lucassen et al., 2013), nutrition (Lindqvist et al., 2006; Beltz et al., 2007; Coupé et al., 2009), and immune activation (Das and Basu, 2008; Green and Nolan, 2014; Musaelyan et al., 2014).

The fact that the hippocampus is particularly susceptible to influences of the early-life environment and in particular stressful stimuli is easily understood when considering the important developmental processes that take place in this brain region during this sensitive developmental period. Indeed, hippocampal and dentate gyrus (DG) development in particular starts during late gestation and continues during the first 2 weeks after birth (Altman and Bayer, 1990), while in human the development of the DG starts during the last trimester of pregnancy and continues to about 16 years of age (Arnold and Trojanowski, 1996). During this time, granular cells are generated in the subventricular zone or in the hippocampus itself, that migrate to the different layers of the DG (Pleasure et al., 2000; Fukuda et al., 2005; Navarro-Quiroga et al., 2006), while in adulthood quiescent neuronal progenitors cells develop to become functional granular cells (Kempermann et al., 2004). Interestingly, adult neurogenesis is lastingly affected by perturbation of the early-life environment as well (Coupé et al., 2009; Oomen et al., 2011; Korosi et al., 2012; Lucassen et al., 2013; Loi et al., 2014; Musaelyan etal., 2014). Next to the generation and migration of granular cells, the migration and colonization by microglia takes place as well during this sensitive period and is also peeking in the first few postnatal days (Schwarz and Bilbo, 2012; Schwarz et al., 2012; Cope and Gould, 2013). These migratory processes are supported by a scaffold formed by immature astrocytes. In addition, glia cells are increasingly acknowledged for there role in the plasticity and circuit functioning of the adult hippocampus (Allen and Barres, 2009; Ekdahl, 2012). Finally, the hippocampus is highly sensitive to stress both early as well as during adult life due to its remarkably high expression levels of the glucocorticoid receptor (GR). Interestingly, expression levels of these receptors have been shown to be affected by early-life stress as well (Liu et al., 1997; Lucassen et al., 2013; de Kloet et al., 2014).

In the following sections we discuss the effects of early-life stress, nutrition, and central immune activity on hippocampal function and adult neurogenesis and thereafter discuss how to implement in these findings that (1) these elements affect one another and (2) they act synergistically to exert their function.

\section{MODULATION OF HIPPOCAMPAL FUNCTION AND NEUROGENESIS BY EARLY-LIFE STRESS}

Early-life stress exposure is strongly associated with cognitive impairments later in life (Kaplan et al., 2001; Stevens et al., 2008; Mueller et al., 2010; Maselko et al., 2011), but what is the preclinical evidence for this association? Which are the most common animal models to study this question?

Stress in the postnatal period can be induced using several rodent paradigms. The most widely studied models to induce early-life stress involve either naturally occurring variation or artificial modulation of maternal care (Francis and Meaney, 1999; Francis et al., 2000), repeated dam-litter separation or a single prolonged deprivation of the dam and her pups (Schmidt et al., 2010; Hedges and Woon, 2011) and chronic early-life stress (Ivy et al., 2008; Rice et al., 2008; Wang etal., 2011) during the first few postnatal weeks. Adult offspring from all of these early-life stress models exhibit cognitive impairments, indicating a strong translational value of these models in addressing the underlying mechanism of such programming. For example, adult rats that had been either maternally separated during the first 2 weeks of life or deprived on postnatal day (P)3 for $24 \mathrm{~h}$, exhibited impairments in their acquisition of spatial information in the Morris water maze (MWM; Oitzl et al., 2000; Huot et al., 2002; Aisa et al., 2007; Fabricius et al., 2008; Oomen et al., 2010) and mice exposed to chronic early-life stress show impairment of spatial memory (tested by MWM and object location) and declarative memory tested by novel object recognition task and Y-maze (Rice et al., 2008; Wang et al., 2011). These early-life stress induced cognitive impairments are associated with a number of alterations in 
hippocampal structure and neuronal plasticity, including decrease in dendritic complexity and spine density in the cornu ammonis (CA) 1 and CA3 (Huot et al., 2002; Ivy et al., 2008; Wang et al., 2011), reduced DG dendritic complexity, granular cell number and granular cell density (Oomen et al., 2010, 2011), reduced astrocyte density in the DG and CA regions (Leventopoulos et al., 2007), and age-dependent alterations in adult hippocampal neurogenesis levels (Korosi et al., 2012). Offspring in both rats and mice exposed to a form of early-life stress exhibit a short-term increase followed by a permanent reduction of proliferating and immature cells (Mirescu et al., 2004; Nair et al., 2007; Oomen et al., 2009, 2010; Hulshof et al., 2011; Suri et al., 2013; Naninck et al., 2014). Levels of cell survival and astrogenesis in young adults are generally not affected after maternal separation (Oomen et al., 2010; Hulshof et al., 2011; Kumar et al., 2011; Suri et al., 2013), but this is strongly reduced at a more advanced age both in rats exposed to low levels of maternal care (Bredy et al., 2003), as well as in mice exposed to chronic early-life stress (Naninck et al., 2014).

How exactly does early-life stress exposure lead to the above described lasting alterations in cognitive functions as well as hippocampal structure and function remains relatively uncertain, but several possible mechanisms of action have been identified over the last years. First, available evidence that early-life stress manipulations, including maternal separation, maternal deprivation or chronic stress via environmental manipulation, alter the quality and/or quantity of maternal care (Brown et al., 1977; Pryce et al., 2001; Macrì et al., 2004; Brunson, 2005; Fenoglio et al., 2006; Korosi and Baram, 2010) strongly suggests that motherinfant interaction is crucial in programming brain and behavior. However, these studies do not directly address whether maternal care, under normal conditions, is actively involved in these regulations.

In support of this notion, it has been demonstrated that a natural variation in maternal care (Liu et al., 1997; Champagne et al., 2008; Bagot et al., 2009) and individual within-litter variation in the amount of active care received (van Hasselt et al., 2012a,b) leads to differences in stress response and cognitive functions associated with altered hippocampal structure, plasticity and changes in the neuroendocrine system in later life. In line with this evidence from animal studies, in pre-term and term neonates, different forms of sensory stimulation, such as moderate touch or skin-to-skin care, have been shown to have beneficial consequences, including reduction of pain responsiveness in neonates (Cignacco et al., 2007) and a reduced reactivity to stress (Feldman et al., 2010). While it is clear that sensory stimuli that the mother gives to her offspring is highly dependent on the well-being of the mother and offspring and thus strongly affected by stressful environment, how exactly this element interacts with the other key elements in the early environment to lead to the programming of the brain structure and function is yet unclear. The few studies tackling the interaction of sensory stimuli with either nutritional or immune challenges are discussed in Sections "The Interplay of the Different Elements in the Early-Life Environment" and "Early-Life Adversity; Opportunities for Intervention Later in Life."

The role of stress-related hormones (corticosterone; CORT) and neuropeptides (e.g., corticotropin releasing hormone, CRH) in the modulation of early-life stress effects on the hippocampus has been studied extensively. When the HPA axis is activated by a stressor this leads to HPA axis activation, which in turn leads to the initial release of $\mathrm{CRH}$ from the hypothalamic paraventricular nucleus (PVN), stimulation of pituitary adrenocorticotropic hormone (ACTH) secretion into the blood, and the subsequent release of glucocorticoids from the adrenal glands: CORT in rodents and cortisol in humans. Negative feedback takes place when glucocorticoids bind to GRs in the hippocampus, PVN, prefrontal cortex and pituitary and thereby inhibit release of CRH and ACTH (Tsigos and Chrousos, 2002).

In fact, exposure to stress during the postnatal early-life period programs the basal and stress-induced activation of the HPA axis and the behavioral responses to stress throughout life (Seckl and Meaney, 2006; Heim and Binder, 2012). Importantly during the first 2 weeks of life, the stress response is believed to be hyporesponsive to some, but not all stressors. This consists of a smaller, or absence of HPA axis responsiveness in pups when compared to the adult organism (Stanton et al., 1988; Levine et al., 1991). Age appropriate stressors, like maternal deprivation or fragmented maternal care elicit secretion of CORT (Yi and Baram, 1994; Schmidt et al., 2004; Rice et al., 2008). There is increasing evidence that next to an increased release of CORT (basally and upon stress exposure), the expression levels of several of the genes involved in the modulation of the stress response (e.g., CRH and GR; Rice et al., 2008; Ivy et al., 2010; Wang et al., 2011; Chen et al., 2012) are lastingly altered in offspring experiencing early-life stress. Thus it is reasonable to assume that these changes might be (at least partly) mediating the altered hippocampal plasticity and thereby the associated cognitive impairments. However, the lasting alterations in the levels of circulating CORT are not consistently permanent in different models of early-life stress (Mirescu et al., 2004; Brunson, 2005; Rice et al., 2008).

While glucocorticoid exposure during early-life evoked cognitive impairments in adulthood (Kamphuis et al., 2003) and there is abundant literature about the regulating (mostly inhibiting) role of CORT (during adulthood) on neurogenesis (Cameron and Gould, 1994; Lucassen et al., 2010), chronic depletion of CORT through adrenalectomy of rats at 10 days of age did, however, not induce alterations in neurogenesis in adulthood (Brunson et al., 2005). Whether the raise in CORT early in life (and no longer in adulthood) modulates the process of neurogenesis and cognitive impairments on the long-term thus remains to be determined. The paucity of data points to the need for further research in this area; however, the contradictory data from the existing studies suggest that other factors may also contribute to the mechanisms by which early-life experience programs brain structure and function.

Because CRH expression is permanently altered after early stress in various models in the hypothalamus (Plotsky and Meaney, 1993; Liu et al., 1997) and hippocampus (Ivy et al., 2010), CRH has been explored as a modulator for the consequence of earlylife stress in the hippocampus (Brunson, 2005; Ivy et al., 2010; Korosi et al., 2010; Wang et al., 2011; Loi et al., 2014). Indeed, exposure to $\mathrm{CRH}$ can mimic the changes in hippocampal structure induced after chronic early-life stress (Brunson, 2005) and a selective blockage of the CRF receptor type 1 during the first 
week after chronic early-life stress indeed prevented the apparent cognitive impairments in the early-life stressed animals (Ivy et al., 2010). Intriguingly, conditional CRF1 knock-out mice were 'protected' against the hippocampus dependent cognitive impairments induced by chronic early-life stress (Wang et al., 2011). Finally early-life stress has been shown to age-dependently affect the expression of the gene and protein of the neurogenic factor brain derived neurotrophic factor (BDNF; Nair et al., 2007; Zimmerberg et al., 2009; Suri et al., 2013). Indeed BDNF expression and concomitant levels of hippocampal neurogenesis are upregulated by early-life stress during development and young adulthood, but reduced to decreased levels with aging (Nair et al., 2007; Suri et al., 2013; Naninck et al., 2014). These data suggests a possible role of BDNF in the modulation of hippocampal plasticity after early-life adversities.

Summarizing, stress related hormones and neuropeptides are involved in mediating lasting effects of early-life stress, however they are not sufficient to explain all the observed effects, indicating that other factors, possibly acting synergistically with these stress molecules, are also involved in the programming. We will next explore the role of nutrition early in life in these processes.

\section{EARLY NUTRITIONAL FACTORS DETERMINE ADULT HIPPOCAMPAL STRUCTURE AND FUNCTION}

As mentioned in the introduction, early nutritional insults have lasting consequences for brain development and function later in life (Lucas, 1998; Brown et al., 2000; McMillen et al., 2008; Prado and Dewey, 2014) with later cognitive functions being particularly affected (de Groot et al., 2011). This is not surprising when considering that during the first postnatal period, the brain is under heavy development and an incredible nutritional demand. In fact, for proper brain development to occur, specific dietary macro-, and micronutrients are essential during gestation and lactation (Scholl et al., 1996; Benton, 2010; Dangat et al., 2010; Veena et al., 2010). Thus, disruption of the nutritional supply (quality and quantity) to the offspring will have major effects on the development of the brain, and more specifically on the hippocampus. An inadequate supply of them during critical developmental periods leads to brain dysfunction and cognitive impairments later in life (McNamara and Carlson, 2006; Innis, 2008; de Groot et al., 2011; Laus et al., 2011).

The offspring is during this critical developmental period fully dependent on the nutrition provided by the mother. Most preclinical models are based upon altering maternal nutrition during gestation and/or lactation. Indeed, micronutrient composition of the maternal diet during gestation and lactation determine the balancing of fatty acid (FA) levels in the brain of the offspring, as maternal micronutrients (Roy et al., 2012) affect the breast milk composition (Innis, 2008; Allen, 2012). The association of early-life nutrition and cognitive functions is further supported by preclinical evidence (Campbell and Bedi, 1989; Castro et al., 1989; de Souza et al., 2011; Valladolid-Acebes et al., 2011; André et al., 2014). Here, we will discuss how early postnatal nutritional stress and specific nutritional components present in the postnatal period modulate cognition and neurogenesis in adulthood.

Various models are used to study how early malnourishment affects brain development and cognitive functions, e.g., through dietary restriction, overnutrition, or malnutrition by limitation of different key elements during gestation and/or lactation. For instance, protein restriction, global dietary restriction to $50 \%$ or high-fat, and modulation of essential macro- and micronutrients that need to be obtained from the diet are commonly used approaches (Campbell and Bedi, 1989; Bedi, 1992; Martinez et al., 2009; Valadares et al., 2010; de Souza et al., 2011; Roy et al., 2012). For example, protein restriction during lactation in rats (Valadares et al., 2010) and $12 \mathrm{~h}$ restriction of maternal milk (Castro et al., 1989) evokes deficits in hippocampus dependent spatial memory tested by MWM and object recognition in adult offspring, but see (Wolf et al., 1986; Campbell and Bedi, 1989). These deficits are accompanied by alterations in hippocampal structure and plasticity as well. Food restriction to $50 \%$ of the normal intake during lactation changed the time course of BDNF production and proliferation in the hippocampus (Coupé et al., 2009) and reduced the number of proliferating cells in the adult offspring, without affecting cell survival or cell fate (Matos et al., 2011). Furthermore, protein restriction during the same period leads to reduced total granular cell numbers (Bedi, 1991) and food restriction to 50\% during gestation and lactation reduced hippocampal volume (Katz et al., 1982). In addition to these nutritional restriction studies, the offspring of high-fat diet exposed dams exhibit a reduction in postnatal neurogenesis during development (Tozuka et al., 2009) and impaired dendritic differentiation of newborn neurons in the adult hippocampus (Tozuka et al., 2010). However, to date no further studies of adult hippocampal neurogenesis in earlylife food-restricted or high-fat diet exposed animals have been performed.

The lipid content during early-life is essential for the composition of maternal milk during lactation and development of the pup brain. For instance, polyunsaturated fatty acids (PUFAs), including the omega-3 FA docosahexaenoic acid (DHA) and omega-6 FA arachidonic acid (AA), are structural components of the brain that promote healthy neuronal growth, repair, and myelination (McNamara and Carlson, 2006). Deficiency of these FAs in the maternal diet first revealed the association of low FA composition and impaired learning and memory functions (Lamptey and Walker, 1978). Moreover, deficiency of omega-3 FA during gestation and lactation impairs the spatial memory (tested by Barnes maze; Fedorova et al., 2009), whereas artificial feeding of rats with omega-3 FA deficient milk during lactation prolonged escape latency in the MWM (Lim et al., 2005) and omega-3 FA enrichment improved performance of the animals (Carrié et al., 2000).

These functional changes following FA deficiency are furthermore associated with structural changes in the brain. Maternal omega-3 FA deficiency during gestation leads to underdevelopment of the primordial hippocampus in fetal rats at the last days of gestation (Bertrand et al., 2006). Nutritional omega-3 FA deficiency during gestation and lactation reduces pyramidal cell size in the hippocampus (Ahmad et al., 2002) and the levels of markers for neuronal plasticity such as BDNF (Madore et al., 2014) at weaning. In addition, dietary enrichment with omega-3 prevents the adverse consequences of early-life sevoflurane (anesthesia) exposure on cell proliferation in the hippocampus and the induced memory impairments (Lei et al., 2013). Maternal supplementation 
of $\alpha$-linolenic acid (ALA), a precursor of omega-3 FA, during gestation and lactation enhanced hippocampal neurogenesis at P19 (Niculescu et al., 2011). However, to date it has not been studied whether an imbalance of FAs in early-life lastingly affects adult hippocampal neurogenesis.

Next to essential FAs, essential amino acids, choline, and methionine, and micronutrients such as folic acid (B9), vitamin B6 and B12, are also essential for brain development (Roy et al., 2012). Deficiency of choline during gestation and lactation impairs working memory in the 12-arm spatial memory maze, while supplementation enhances performance (Meck and Williams, 1999). In addition, a deficiency of nutritional folate, choline, B6, and B12 during gestation and lactation leads to learning and memory impairments in the radial arm mazes and enhanced the number of apoptotic cells in the hippocampus (Blaise et al., 2007). Deficiency of these methyl donors furthermore affects hippocampal neurogenesis by altering the apoptotic rate (Craciunescu et al., 2010).

Summarizing, evidently the nutritional composition during critical developmental periods (pre and postnatal) of life is essential for the proper development, structure and function of the hippocampus. Similar to the cognitive impairments induced by early-life stress, early-life malnutrition evokes such deficits as well. Another important element known to play a key role in modulating brain development and function is the neuroimmune system, which will be discussed in the next section.

\section{EARLY-IMMUNE RESPONSE ACTIVATION PROGRAMMING THE LATER-LIFE HIPPOCAMPUS}

Activation of the peripheral and/or central immune system in early-life is associated with psychopathologies in adulthood, including cognitive dysfunction (Rantakallio et al., 1997; O'Connor et al., 2014). For instance, maternal infection during pregnancy is associated with lower IQ in adult men (Eriksen et al., 2009). In addition, pre- and postnatal infection have been associated with anxiety-like and depressive-like behavioral responses and cognitive impairments in adolescence and adulthood (Das and Basu, 2011; Williamson et al., 2011; Doosti et al., 2013; Dinel et al., 2014). The modulating effects of early-life immune challenges on brain function are not unexpected considering the essential role of neuroimmune cells in (early-)life. Microglia and astrocytes mediate many processes in the brain, including neuroinflammatory responses (Capuron and Miller, 2011; Green and Nolan, 2014; O'Connor et al., 2014), neuronal activation and plasticity (Slezak et al., 2006; Halassa et al., 2009; Parpura et al., 2012; Greter and Merad, 2013), maintenance and development of the blood-brain barrier (BBB; Banks et al., 1995; Chaboub and Deneen, 2013) and importantly, neurogenic processes during development (Das and Basu, 2011; Schwarz and Bilbo, 2012; Cope and Gould, 2013) and adulthood (Das and Basu, 2008; Ekdahl, 2012; Cope and Gould, 2013; Cunningham et al., 2013; Kohman and Rhodes, 2013; Sierra et al., 2013, 2014). Thus, imbalanced activation of the microglia, in particular during early-life, has the potential to lastingly disturb internal homeostasis and proper brain development (Allen and Barres, 2009).

Activity of the microglia is controlled by immune response regulating effector molecules, like pro-inflammatory (e.g., IL-1 $\beta$,
IL-6, and TNF $\alpha$ ) and anti-inflammatory (e.g., IL-4 and IL-10) cytokines or chemokines (Chaplin, 2003; Cartier et al., 2005; Ekdahl etal., 2009) that regulate the communication between immune cells in the peripheral and central immune system. Although the brain is a relatively concealed and immunosuppressed environment in adulthood, that is separated from the periphery by the BBB, cytokines, and chemokines in the periphery have the potential to cross the $\mathrm{BBB}$ and can affect the innate cells of the brain (Banks etal., 1995; Pan and Kastin, 1999). Interestingly, during early-life, peripheral immune challenges might have a greater potential to adversely affect the brain (Schoderboeck et al., 2009). During this time, the BBB still preexists in a leaky stage till a few days after birth (Engelhardt, 2003), providing the possibility of a greater immunoreactive responses in the brain when a peripheral infection occurs. In addition, microglia develop in close parallel to developmental neurogenesis and appear in an activate and amoeboid state during development, whereas they are present as resting, ramified cells in adulthood (Bilbo and Schwarz, 2009).

In the following part, we will discuss the pre-clinical evidence in support of a direct role of postnatal immune challenges in the persistent modulation of hippocampal structure and function. Most studies of postnatal infection have focused on stimulation by bacteria like Escherichia coli or the Gram-negative bacteria component lipopolysaccharide (LPS). We will here address the hippocampus dependent cognitive functions following early-life neuroimmune stress from two different angles. Firstly, activation of the peripheral neuroimmune system and its immediate and lasting effects on central neuroimmune system function and brain function. Secondly, the consequences of central neuroimmune system activity without a prior peripheral immune challenge, for instance via activation of central viral infection or proinflammatory factors, on hippocampal function and neurogenesis in adulthood.

A peripheral immune challenge with LPS (P1) or E. coli (P4) in the rat pup elicits an elevation of pro-inflammatory cytokines and CORT in the first few hours after the challenge in blood serum (Bilbo etal., 2005b), whole brain (Ortega etal., 2011) or hippocampus (Bilbo et al., 2005b; Dinel et al., 2014). In adulthood, cytokine mRNA expression levels in the brain of the early-infected animals remain normal under basal conditions, with the exception of elevated hippocampal levels of TNF $\alpha$ (P4 infected; Bland et al., 2010a) and IL-1 $\beta$ (P5 LPS infected; Wang et al., 2013). Although overall no strong changes in the cytokine expression profiles are present in the adult, in the early-life infected animals, microglial activation markers indicate enhanced reactive microglia (CD11b+) in the hippocampus (Bilbo et al., 2005a) and CA1 region (Iba1+; Bland et al., 2010b). In addition, adult rats exposed to LPS at P3 and P5 exhibited a hippocampusspecific increase in Iba1+ immunoreactive microglia in the CA1 and DG (Sominsky et al., 2012), indicative of a priming effect on hippocampal microglia. Indeed, a peripheral LPS injection in adulthood exerts an exaggerated pro-inflammatory cytokine response of mainly IL- $1 \beta$ in the hippocampal CA1 of rats with a history of early-life infection (Bilbo et al., 2005a, 2008), probably evoked by a programmed pro-inflammatory response of hippocampal microglia. 
Interestingly, the pro-inflammatory response in the hippocampus following peripheral infection is accompanied by a direct effect on developmental hippocampal neurogenesis and structural changes in adulthood. E. coli infection at P4 immediately suppresses gene expression of neurotropic factor BDNF in the CA1 and CA3 (Bilbo et al., 2008) and neuronal and astrocytic cell proliferation is reduced in the hippocampus following LPS exposure at P9 (Järlestedt et al., 2013). Hippocampal cell proliferation then restores to normal conditions in the $48 \mathrm{~h}$ after the challenge and does not affect the survival of immature neurons during the time of infection (Bland et al., 2010a; Järlestedt et al., 2013). This developmental change probably underlies the reduction in later hippocampal volume observed in early-life infected adult rodents (Wang et al., 2013). Moreover, in adulthood, early-life $E$. coli infected rats and LPS infected mice have comparable numbers of dividing, differentiating, and surviving neurogenic cells in the subgranular zone as control animals (Bland et al., 2010b; Järlestedt et al., 2013; Dinel et al., 2014). In conclusion, neurogenesis does not seem to be heavily affected by peripheral immune challenges. These subtle changes in neurogenesis are in line with the findings of limited effects on hippocampus-related cognitive functioning as well. Most studies of early-life infection do not find changes in different learning and memory paradigms, such as fear conditioning, MWM or Y-maze (Bilbo et al., 2005a, 2007, 2008; Dinel et al., 2014), but see (Harré et al., 2008; Wang et al., 2013). Interestingly, however, a stronger modulation of hippocampus-related cognitive functions is manifested after a second immunological challenge in early-life infected rodents. Thus, a combination of early-life infection history and adolescent or adult LPS (re-)exposure evokes impairments in a contextual fear conditioning paradigm (Bilbo et al., 2005a, 2006) and spatial memory performance in the Ymaze (Dinel etal., 2014), but not in the MWM (Bilbo et al., 2007).

Interestingly, these cognitive impairments in response to a second immune challenge appear in accordance with reduced newborn cell survival in the early-infected rats (Bland et al., 2010a), but not with BDNF gene expression levels (Bilbo et al., 2008). In contrast, neurogenesis is upregulated after LPS during adulthood in animals that never had an immune challenge before (Bland etal., 2010a). The consequences of a second immunological challenge in adulthood might thus be resulting from the priming effects of an early-life infection on the population of adult hippocampal microglia. This may lead to an exaggerated pro-inflammatory response with detrimental effects on adult hippocampal neurogenesis and cognition.

Neuroimmune system activation is not solely induced by peripheral bacterial components. The consequences of direct modulation of central cytokines and/or central induction of innate immune cells on the hippocampus are moderately studied. An example is TNFa injection at P3 and P5, increasing anxietylike behaviors in male mice (Babri et al., 2014b). However, other cytokine overexpression levels have not been elegantly studied. For some years now, viral infections have been considered a contributing factor to the development of neuropsychological disorders, including hippocampal related dysfunction (Das and Basu, 2011). Various viruses are used to investigate disruption in hippocampal development and adult neurogenesis, e.g., the lymphocytic choriomengitis virus (LCMV) (Pearce et al., 1996; Sharma et al., 2002; Orr et al., 2010), Borna disease virus (BDV; Zocher et al., 2000; Sauder et al., 2001) or polyinosinic:polycytidylic acid (Poly I:C; Galic et al., 2009). Each of these viruses induces different phenotypical changes. Poly I:C intracerebroventricular injection at P14 induces short time elevations of pro-inflammatory cytokine IL-1 $\beta$ in the hippocampus and adult-onset deficits in contextual fear conditioning (Galic et al., 2009). But earlier central administration of LCMV at $\mathrm{P} 4$ produces lasting IL-1 $\beta$ induction with subsequent loss of cells in the granular cell layer (Sharma et al., 2002; Orr et al., 2010) and reduced levels of progenitor cells in the DG (Sharma et al., 2002), without affecting other hippocampal regions (Pearce et al., 1996). This virus induced phenotype could be reduced by the use of an anti-inflammatory agent to block IL-1 $\beta$, which restored the granular cell numbers in adulthood (Orr et al., 2010). The BDV virus typically induces apoptosis of DG cells at 27 and 33 days post infection, possibly mediated by a reduction in neurotrophins in this brain region (Zocher et al., 2000) and further impairs MWM performance in adulthood, correlating to chemokine expression levels (Sauder et al., 2001). How these virus infections early in life mechanistically affect the hippocampus is unfortunately poorly understood to date (Das and Basu, 2011).

Altogether, early-life peripheral infection immediately increases pro-inflammatory cytokines in the hippocampus and exerts lasting effects on hippocampal structure, but evokes only subtle alterations in hippocampal neurogenesis and functionality under basal condition. After exposure to a second immunological challenge in adulthood, however, a history of early-life infection has aversive effects on cognitive function related to an exaggerated pro-inflammatory response in the hippocampus. On the other hand, viral infection that induces a central stimulation of the immune system leaves detrimental effects on the DG, affecting adult hippocampal neurogenesis and cognitive functions. The lasting effect of early-life infection on hippocampal microglia suggests that a programming effect of peripheral and ultimately central immune system activity plays an important role in the lasting effects of hippocampal structure and cognitive functions.

\section{THE INTERPLAY OF THE DIFFERENT ELEMENTS IN THE EARLY-LIFE ENVIRONMENT}

The discussed consequences of early-life stress, nutrition, and immune activation can all be considered forms of early-life adversity. Although limited studies have examined the integrated role of these elements, the presented evidence in the above sections clearly points to the fact that challenges, even when very different in nature (disruption of maternal care, malnutrition, or immune), lead to strikingly similar outcomes of disrupted hippocampal structure and plasticity later in life as well as cognitive impairments. Knowing that these systems are tightly related and that they affect each other, it is reasonable to assume that the current models of early-life stress, malnutrition and infections discussed up to now elicit effects on all these different levels (Figure 1) and that it is the synergistic effects of all of these components that lead to the observed outcome rather than only the experimentally modulated one. In the upcoming section, we will discuss the current evidence and missing links for this hypothesis. Because the 


\section{Early-life adversity}

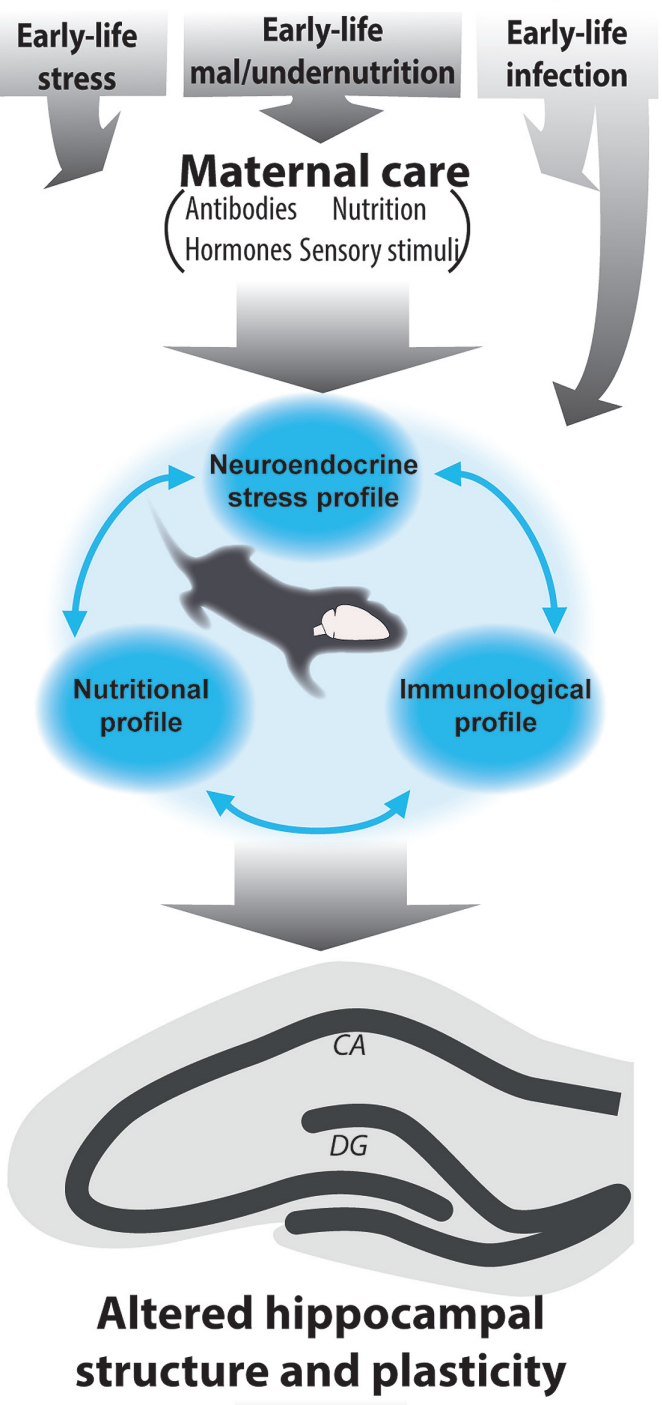

\section{Cognitive impairments in adulthood}

FIGURE 1 | Schematic representation of the interrelated role of different early-life elements for the consequences of early-life adversity. Early-life adversities in the form of early-life stress, under/malnutrition and infection are known to modulate hippocampal development and altogether determine hippocampal structure and function in adulthood with adverse effects on learning and memory. During the early sensitive period of development the offspring is fully dependent on the mother. Maternal care encompasses several elements (sensory stimuli, transfer of nutrition, hormones, and antibodies). In fact it is mostly via disruption of maternal care (with exception of early-life infection which can directly act upon the offspring) that early adversities will elicit disruptions in hormonal, (neuro)inflammatory and nutritional profiles in the offspring. Because these elements affect one another, they will ultimately act synergistically to modulate hippocampal structure and function throughout life. tight interaction and possible synergistic effects of stress and nutrition on neurocognitive development has been recently reviewed and discussed both prenatally (Monk et al., 2013) as well as postnatally (Lucassen et al., 2013), we will here focus on the interaction of early-life stress and malnutrition with the immune activation.

\section{WHAT IS THE EVIDENCE FOR AN INTERACTION BETWEEN EARLY-LIFE IMMUNE ACTIVATION AND EARLY-LIFE ADVERSITY?}

Early-life adversities like stress and malnutrition not only lead to the previously described effects on cognitive and hippocampal function but also to changes in adult immunological function. The stress and immune systems have a strong interactive profile, illustrated by, e.g., the immune-suppressive effect of corticosteroids (Tsigos and Chrousos, 2002; Chaplin, 2010). Evidence of this relation in early-life has been provided by the enhanced pro-inflammatory status, both basally as well as in response to stress (Carpenter et al., 2010; Chen et al., 2010), of adult individuals with a history of early-life adversity, such as children raised in poor socioeconomic status households or who suffered from childhood maltreatment. This association has been confirmed by preclinical studies as well. In general, early-life stress paradigms (pre- and postnatal) lead to an immediate immunosuppressive state, e.g., a reduced lymphoproliferative response of the thymus (Llorente etal., 2007), downregulation of antiinflammatory IL-10 and pro-inflammatory IL- $1 \beta$ (Dimatelis et al., 2012) and reduction of lipobinding protein (LBP), that regulates innate immune system pathogen presentation by microglia cells (Wei et al., 2012). These alterations in the immunoreactive profile in early-life are further accompanied by central changes in microglia morphology and number of Ibal (Diz-Chaves et al., 2012) or lectin immunoreactive cells (Gómez-González and Escobar, 2009b).

In adulthood, the programming effect of early-life adversity by maternal deprivation on immune regulation is further illustrated by enhanced IL- $1 \beta$ responsiveness due to elevated IL-1 receptor levels at the post-synapse of adult hippocampal neurons (Viviani et al., 2013). In addition, the inflammatory response to an inflammatory challenge (systemic LPS injection) in the hippocampus of prenatally stressed mice is exaggerated in the reactivity of microglia and expression of pro-inflammatory cytokines (Diz-Chaves et al., 2013). Altogether, early-life stress tends to have a programming effect on neuroimmune functions, mainly resulting in an immediate immunosuppressive, but pro-inflammatory state in adulthood, which triggers an exaggerated neuroimmune response defined by cytokine secretion and microglia activity upon an immune challenge. How the early-life adversity-induced pro-inflammatory adult profile in the brain interacts with the other changes in brain structure and how these altogether lead to the observed cognitive impairments needs to be further investigated.

Next to the evident programming effects of early-life stress on neuroimmune functions, possible lasting effects of inflammatory challenges during early-life on HPA axis activity need to be considered as well. Early-life infection generally leads to a direct elevation of circulating glucocorticoids in early-life (Bilbo et al., 2005a) and while basal CORT was not affect by early-life infection at P14, the level of phosphorylated GR is significantly higher in the prefrontal cortex, but not the hippocampus (Dinel et al., 2014). In 
contrast, early infection does not affect basal and/or stress-induced CORT in a lasting manner (Bilbo et al., 2006; Walker et al., 2010; Babri et al., 2014a; Dinel et al., 2014). In line with this, CORT secretion following adult LPS exposure seems independent of the early-life history of exposure to stress or infection (Bilbo et al., 2005a, 2007; Kohman et al., 2008). However there is evidence indicating that early-life infected animals exhibit prolonged CORT elevations accompanied by a greater content of pro-inflammatory IL- $1 \beta$ and TNF $\alpha$ in the hippocampus upon adult stress exposure (Walker etal., 2010) while exposure to high doses of the pro-inflammatory cytokine TNF $\alpha$ increased stress-induced CORT release (Babri et al., 2014b).

Clearly, in the activation of neuroimmune cells induced either by a peripheral immune challenge or by early-life adversity, the $\mathrm{BBB}$ plays a pivotal role. There is evidence that development of the $\mathrm{BBB}$ is hampered after exposure to perinatal stress and exposure to an early-life immune challenge, revealing elevated BBB leakage in among other areas the hippocampus (Gómez-González and Escobar, 2009a). Whether these changes in early-life stress induced BBB leakage are related to changes in neuroimmune functioning after early-life stress remains to be determined.

\section{WHAT IS THE EVIDENCE FOR AN INTERACTION BETWEEN EARLY-LIFE MALNUTRITION AND NEUROIMMUNE ACTIVATION?}

Next to early-life stress, also early-life nutritional insults can affect the neuroimmune system. For example, there are indications for a strong association between circulating leptin levels and the suppression of lymphoproliferative responses and pro-inflammatory cytokine secretion in protein malnourished infants, both before and after recovery following refeeding (Palacio et al., 2002).

Similar indications are provided by preclinical studies where adult offspring of food-restriction dams have increased basal immune activity (measured as C-reactive protein) in female offspring at 9 months of age, but reduced cytokine induction (IL-1 $\beta$ and IL-6 secretion) in response to a second immune insult with LPS (Desai et al., 2009). Similarly, adult offspring of dams that were protein-deprived during lactation show an impaired responsiveness to a peripheral immune challenge, that was accompanied by elevated levels of basal and response CORT (Barja-Fidalgo et al., 2003). Lipid content of the diet early in life seems to be a strong modulator of neuroimmune functioning throughout life. Indeed, offspring of dams fed high-fat and high-trans fat during pregnancy and lactation exhibit increased basal immune activity (C-reactive protein) at birth and increased active microglia in adult (Bilbo and Tsang, 2010) associated with improved performance in the MWM. These basal changes are accompanied by an exaggerated peripheral and hippocampal IL- $1 \beta$ response to adult LPS (Bilbo and Tsang, 2010), classically known to activate microglia (Van Dam et al., 1992). Interestingly, when maternally deprived rats (P9) are weaned on a high fat diet during adult life, they present an increased pro-inflammatory modulation of IL- $1 \beta$ and TNF $\alpha$ in the hypothalamus (Mela et al., 2012). Omega-3 FAs in particular appear responsible for these observations as they activate neuroprotective signaling pathways (Calon and Cole, 2007) and act upon immune regulators, by, e.g., blockage of the NFKB signaling pathway (Singer et al., 2008). In fact, male offspring of omega3 deficient dams exhibit a promotion of reactive inflammatory microglia and elevated pro-inflammatory cytokines in the hippocampus at P21 (Madore et al., 2014). It remains elusive how the changes in dietary fat composition early in life and subsequent priming of microglia further relate to levels of adult hippocampal neurogenesis.

One of the possible mediators of the interaction between nutritional intake and immune system is leptin, which is secreted by white adipose tissue (Fernández-Riejos et al., 2010). In fact, rats treated with LPS at P10 have increased food intake in adulthood associated with elevated circulating leptin levels. A second immune challenge (LPS at 7-8 weeks of age), while leading to an elevation in leptin serum level in animals that were never exposed to infection before, did not alter leptin levels in the neonatally infected animals (Iwasa et al., 2010). Moreover, neonatal overfeeding, similarly to the combination of early-life stress and a high fat diet as discussed above (Mela et al., 2012), leads to microgliosis in the hypothalamic regions, including the PVN of the hypothalamus, a key nucleus in the regulation of HPA axis activity that can be triggered by interleukin-1 as well (Berkenbosch et al., 1987). Especially in this region, microglia activation is overly exaggerate upon an immune challenge with LPS in adulthood (Ziko et al., 2014). Interestingly, these manipulations lead to a disruption in the patterns of leptin, coinciding with the leptin surge for normal hypothalamic development (Ahima et al., 1998; Ahima and Hileman, 2000). Thus, a disrupted pattern of leptin secretion and induced (neuro) inflammation by these manipulations may play an important role in programming of the cognitive functions (Miller and Spencer, 2014). It is remarkable that entirely different manipulations as prenatal stress (Diz-Chaves et al., 2013), being raised by a dam exposed to high fat diet during pregnancy and lactation (Bilbo and Tsang, 2010) and neonatal overfeeding (Ziko et al., 2014) reset the neuroimmune function and lead to exaggerated microgliosis in response to a subsequent immune challenge in adulthood.

Although not extensively studied during early-life, current evidence on the dietary supply of methyl donors modulating the present levels of homocysteine in the (developing) brain (Blaise etal., 2007; Troen etal., 2008), with a deficiency leading to hyperhomocysteinemia, further suggests a role for dietary methyl donors in microglia properties and activity in adulthood. Hyperhomocysteinemia is associated with an elevated levels of homocystein-presenting apoptotic cells, and also with enhanced proliferation of microglia in the brain (Zou et al., 2010). Moreover, hyper-homocysteinemia can be a risk factor or marker of neurodegenerative disorders in which cognitive dysfunction and neuroimmune functioning play an important role (Morris, 2003; Van Dam and Van Gool, 2009). However, to date, the exact relation of early-life methyl donor supply and neuroimmune functions remains elusive.

Exciting new evidence further supports a strong interaction between nutrition and immune system in the programming of hippocampal structure and function. A recent paper by Liu et al. (2014) proposed a pathway of "lactocrine" programming of hippocampal development and function by maternal deficiency of $\mathrm{TNF} \alpha$, resulting in altered chemokine composition of the mother. In fact, TNF $\alpha$ deficiency in mothers milk lead to impaired hippocampal proliferation and spatial memory in the offspring of 
these animals, a clear indication of programming via nutritionally provided immune effector messengers (Liu et al., 2014). The exact pathway of TNF $\alpha$ and the role of chemokines that lead to alterations in hippocampal development, adult learning and memory, remains to be explored (Parylak et al., 2014).

Altogether, dietary composition during critical sensitive periods of development seem to be strongly involved in the immediate and lasting effects on the innate immune system, with a tendency to an immediate immunosuppressive response being associated with protein and fat malnourishment, and an enhanced proinflammatory activity induced by high fat diets associated with an sub-optimal neuroimmune response (too little or exaggerated) in response to later life immune challenges. How the early-life nutrition directly programs neuroimmune function and interacts with the neuroendocrine system, and programs cognitive functions and hippocampal neurogenesis in later life requires further study.

In the previous section we have highlighted some of the key elements of the early-life environment that might play an important role in the programming of cognitive functions by early-life adversity. As evident from the studies that we discussed these elements clearly do not act alone but rather in a synergistic manner. We discussed some of the possible mechanisms that could mediate the effects of early-life stress, malnutrition, and infection and discussed the evidence for their interactive profile. However clearly our discussion is not exhaustive and other equally important paths and mediators responsible for the final programming effect could be considered. For example, next to leptin, ghrelin a pancreatic hormone released upon hunger can influence not only eating behavior but stress, immune function as well as cognition (Diz-Chaves, 2011). Clearly having to consider so many different elements simultaneously renders the picture very complex and questions which are the best systems to target to prevent and/or reverse the deleterious effects of early-life adversity. In the following section, we will discuss some of the intervention strategies that have been explored up to date.

\section{EARLY-LIFE ADVERSITY; OPPORTUNITIES FOR INTERVENTION LATER IN LIFE}

Adversities in the early-life period provoke thus immediate and programmed effects on different levels with lasting consequences for hippocampal function. Identification of these consequences and the different systems at play during early-life is essential to design optimal intervention studies to counteract the more complete set of consequences following early-life adversity. In recent years, multiple intervention studies have been performed to counteract either the lack of nutritional components, the consequences of early-life stress or the pro-inflammatory state after early-life infections. For instance, clinical research revealed the potential of high levels of maternal warmth (regarded as a positive experience) to overcome the programmed effects of the aversive low socioeconomic status on the immune system during early-life (Chen et al., 2010). However, considering the evidence presented in this review that these systems interact and affect each other so tightly and that they might thus act synergistically to program brain structure and function for life, the question arises as to which consequences of early-life adversity to target and whether there is a crucial time window for these interventions for optimal beneficial effects of these interventions. Here, we will discuss a few examples of potential intervention studies.

Because changes of HPA axis modulators are suggested as potential regulators of the lasting changes following early-life stress, suppression of these modulators has been investigated as a possible intervention in later life. For example, selective blockage of CRF receptor 1 immediately after the first week after chronic early-life stress exposure from postnatal day 10-17 in rats prevents hippocampal impairments in cognitive functioning and long-term potentiation (Ivy et al., 2010).

Enriching the later life environment, a manipulation that is known to stimulate hippocampal neurogenesis and improve performance of hippocampus related spatial behavioral tasks in adulthood (Kempermann et al., 1997; Nilsson et al., 1999), has been explored as well. For example, housing maternally separated rats in an enriched environmental condition during adulthood reversed the early-life stress induced changes in hippocampal GR and CRF expression (Francis et al., 2002). These manipulations do not only modify HPA axis activity but also affect neuroimmune functioning and activity of glial cells (Olah et al., 2009; Williamson et al., 2012; Gebara et al., 2013). In addition, there is evidence that enriching early-life environment by artificially increasing sensory stimuli by the mother (via handling) interferes with the adult proinflammatory programming of early-life E. coli infection (Bilbo et al., 2007). The adult LPS-induced increase of microglia (CD11b) and astrocyte (GFAP) markers and IL-1 $\beta$ levels in the blood and different brain regions of animals with a history of E. coli exposure was fully prevented by early-life handling. These data clearly suggest a strong interaction between sensory stimuli and infection early in life in the programming of the adult neuroimmune system (Bilbo et al., 2007).

A final manner to intervene with the consequences of earlylife stress is modulation at the level of the epigenome. Early-life stress and early-life nutrition program later life function through alterations in chromatin structure and gene expression as became evident from clinical and animal studies. There is indeed increasing evidence that epigenetic mechanisms might be responsible for the early-life adversity induced life-long alterations in gene expression. (Heijmans et al., 2008; Murgatroyd et al., 2009; SteegersTheunissen et al., 2009; Canani et al., 2011; Chen et al., 2012; Lucassen et al., 2013). Moreover, epigenetics mechanisms play a role in neuroinflammatory responses as well (Garden, 2013). Which are the factors regulating epigenetic mechanisms is yet unclear, however, there is growing interest in the role that nutrition might play in this context (Lucassen et al., 2013; Spencer, 2013). Nutritional interventions to prevent or reverse these epigenetic alterations have been only explored concerning metabolic programming but might certainly have the potential to intervene with the deleterious programming by early-life adversity of brain structure and function (Lucassen et al., 2013). For instance, folic acid supplementation to the offspring of protein-restricted diet fed dams during adolescence altered the protein-restricted metabolic outcome and modified the epigenetic alterations (Burdge et al., 2009). In addition, folate deficiency of the maternal diet during gestation negatively influences hippocampal developmental neurogenesis, but supplementation with the interrelated methyl donor 
choline modified some of these effects on the neural progenitor cells (Craciunescu et al., 2010). But can dietary intervention later in life prevent or reverse the early-life adversity induced phenotype? Weaver etal. (2005) provided evidence that the programming effect of maternal care during early-life on the epigenetic modifications of the GR remain sensitive to alterations in adulthood, as central infusion with L-methionine could reverse the programmed effects of maternal care.

Overall, these studies indicate that environmental, nutritional, and pharmacological interventions, either during early-life or in adulthood, have the potential to modulate one or more consequences of early-life adversity. Currently, intervention studies lack some depth on the interplay of stress mediators, neuroimmune activity and the nutritional profile in how they might synergistically modulate hippocampal structure and function. Addressing the complexity of the early-life environment at large, rather than focusing on a single element will provide the necessary information to design new interventions, or a combination of interventions, that may fully prevent and/or reverse the consequences of early-life adversity.

\section{FINAL CONCLUSION}

Well-known factors such as genetic vulnerability, gender, life style, and aging contribute to disorder vulnerability. In addition, earlylife adversity further determines brain susceptibility to develop adult-onset psychopathologies and cognitive impairments later in life. Multiple elements (including stress, nutrition, and infections) in the early-life environment are crucial for proper hippocampal development, and structure and function in adulthood. Thus there is growing evidence that disruption of either of these elements has detrimental effects on cognitive functions, hippocampal structure, neurogenesis and the activity of neuroimmune cells in the hippocampus. Here, we have focused on how these different elements might interplay during early-life adversity and elicit similar effects on hippocampal neurogenesis and cognition in adulthood. Even though the interplay of these three elements is generally not considered in depth, the ultimate consequences are probably a synergistic effect and combination of these elements. Considering the intense cross talk between these elements and how they, together, program hippocampal structure and function, will provide important insights and contribute to novel targets for pharmacological, nutritional or life style interventions after early-life adversity.

\section{ACKNOWLEDGMENTS}

Lianne Hoeijmakers and Paul J. Lucassen are supported by Alzheimer Nederland, Paul J. Lucassen and Aniko Korosi are supported by ISAO and Paul J. Lucassen is supported by NWO PRIOMED and the HersenStichting Nederland.

\section{REFERENCES}

Ahima, R. S., and Hileman, S. M. (2000). Postnatal regulation of hypothalamic neuropeptide expression by leptin: implications for energy balance and body weight regulation. Regul. Pept. 92, 1-7. doi: 10.1016/S0167-0115(00)00142-7

Ahima, R. S., Prabakaran, D., and Flier, J. S. (1998). Postnatal leptin surge and regulation of circadian rhythm of leptin by feeding. Implications for energy homeostasis and neuroendocrine function. J. Clin. Invest. 101, 1020-1027. doi: 10.1172/JCI1176
Ahmad, A., Moriguchi, T., and Salem, N. (2002). Decrease in neuron size in docosahexaenoic acid-deficient brain. Pediatr. Neurol. 26, 210-218. doi: 10.1016/S0887-8994(01)00383-6

Aisa, B., Tordera, R., Lasheras, B., Del Rio, J., and Ramirez, M. J. (2007). Cognitive impairment associated to HPA axis hyperactivity after maternal separation in rats. Psychoneuroendocrinology 32, 256-266. doi: 10.1016/j.psyneuen.2006.12.013

Allen, L. H. (2012). B Vitamins in breast milk: relative importance of maternal status and intake, and effects on infant status and function. Adv. Nutr. 3, 362-369. doi: 10.3945/an.111.001172

Allen, N. J., and Barres, B. A. (2009). Glia - more than just brain glue. Nature 457, 675-677. doi: 10.1038/457675a

Altman, J., and Bayer, S. A. (1990). Migration and distribution of two populations of hippocampal granule cell precursors during the perinatal and postnatal periods. J. Comp. Neurol. 301, 365-381. doi: 10.1002/cne.903010304

André, C., Dinel, A., Ferreira, G., Layé, S., and Castanon, N. (2014). Diet-induced obesity progressively alters cognition, anxiety-like behavior and lipopolysaccharide-induced depressive-like behavior: focus on brain indoleamine 2,3-dioxygenase activation. Brain Behav. Immun. 41, 10-21. doi: 10.1016/j.bbi. 2014.03.012

Arnold, S. E., and Trojanowski, J. Q. (1996). Human fetal hippocampal development: I. Cytoarchitecture, myeloarchitecture, and neuronal morphologic features. J. Comp. Neurol. 367, 274-292. doi: 10.1002/(SICI)10969861(19960401)367:2<274::AID-CNE9>3.0.CO;2-2

Babri, S., Doosti, M.-H., and Salari, A. (2014a). Strain-dependent effects of prenatal maternal immune activation on anxiety- and depression-like behaviors in offspring. Brain Behav. Immun. 37, 164-176. doi: 10.1016/j.bbi.2013.12.003

Babri, S., Doosti, M.-H., and Salari, A. (2014b). Tumor necrosis factor-alpha during neonatal brain development affects anxiety- and depression-related behaviors in adult male and female mice. Behav. Brain Res. 261, 305-314. doi: 10.1016/j.bbr.2013.12.037

Bagot, R. C., van Hasselt, F. N., Champagne, D. L., Meaney, M. J., Krugers, H. J., and Joëls, M. (2009). Maternal care determines rapid effects of stress mediators on synaptic plasticity in adult rat hippocampal dentate gyrus. Neurobiol. Learn. Mem. 92, 292-300. doi: 10.1016/j.nlm.2009.03.004

Bale, T. L., Baram, T. Z., Brown, A. S., Goldstein, J. M., Insel, T. R., McCarthy, M. M., et al. (2010). Early life programming and neurodevelopmental disorders. Biol. Psychiatry 68, 314-319. doi: 10.1016/j.biopsych.2010.05.028

Banks, W. A., Plotkin, S. R., and Kastin, A. J. (1995). Permeability of the blood-brain barrier to soluble cytokine receptors. Neuroimmunomodulation 2, 161-165. doi: $10.1159 / 000096887$

Barja-Fidalgo, C., Souza, E. P. G., Silva, S. V., Rodrigues, A. L., Anjos-Valotta, E. A., Sannomyia, P., et al. (2003). Impairment of inflammatory response in adult rats submitted to maternal undernutrition during early lactation: role of insulin and glucocorticoid. Inflamm. Res. 52, 470-476. doi: 10.1007/s00011-003-1207-3

Barker, D. (2004). Developmental origins of adult health and disease. J. Epidemiol. Community Health 58, 114-115. doi: 10.1136/jech.58.2.114

Barker, D., Barker, M., Fleming, T., and Lampl, M. (2013). Developmental biology: support mothers to secure future public health. Nature 504, 209-211. doi: 10.1038/504209a

Bedi, K. S. (1991). Early-life undernutrition causes deficits in rat dentate gyrus granule cell number. Experientia 47, 1073-1074. doi: 10.1007/BF01923346

Bedi, K. S. (1992). Spatial-learning ability of rats undernourished during early postnatal life. Physiol. Behav. 51, 1001-1007. doi: 10.1016/0031-9384(92)90084-F

Beltz, B. S., Tlusty, M. F., Benton, J. L., and Sandernan, D. C. (2007). Omega3 fatty acids upregulate adult neurogenesis. Neurosci. Lett. 415, 154-158. doi: 10.1016/j.neulet.2007.01.010

Benton, D. (2010). The influence of dietary status on the cognitive performance of children. Mol. Nutr. Food Res. 54, 457-470. doi: 10.1002/mnfr.200900158

Berkenbosch, F., van Oers, J., del Rey, A., Tilders, F., and Besedovsky, H. (1987). Corticotropin-releasing factor-producing neurons in the rat activated by interleukin-1. Science 238, 524-526. doi: 10.1126/science.2443979

Bertrand, P. C., O'Kusky, J. R., and Innis, S. M. (2006). Maternal dietary (n-3) fatty acid deficiency alters neurogenesis in the embryonic rat brain. J. Nutr. 136, 1570-1575.

Bilbo, S. D., Barrientos, R. M., Eads, A. S., Northcutt, A., Watkins, L. R., Rudy, J. W., et al. (2008). Early-life infection leads to altered BDNF and IL-1beta mRNA expression in rat hippocampus following learning in adulthood. Brain Behav. Immun. 22, 451-455. doi: 10.1016/j.bbi.2007.10.003 
Bilbo, S. D., Biedenkapp, J. C., Der-Avakian, A., Watkins, L. R., Rudy, J. W., and Maier, S. F. (2005a). Neonatal infection-induced memory impairment after lipopolysaccharide in adulthood is prevented via caspase- 1 inhibition. J. Neurosci. 25, 8000-8009. doi: 10.1523/JNEUROSCI.1748-05.2005

Bilbo, S. D., Levkoff, L. H., Mahoney, J. H., Watkins, L. R., Rudy, J. W., and Maier, S. F. (2005b). Neonatal infection induces memory impairments following an immune challenge in adulthood. Behav. Neurosci. 119, 293-301. doi 10.1037/0735-7044.119.1.293

Bilbo, S. D., Newsum, N. J., Sprunger, D. B., Watkins, L. R., Rudy, J. W., and Maier, S. F. (2007). Differential effects of neonatal handling on early life infectioninduced alterations in cognition in adulthood. Brain Behav. Immun. 21, 332-342. doi: 10.1016/j.bbi.2006.10.005

Bilbo, S. D., Rudy, J. W., Watkins, L. R., and Maier, S. F. (2006). A behavioural characterization of neonatal infection-facilitated memory impairment in adult rats. Behav. Brain Res. 169, 39-47. doi: 10.1016/j.bbr.2005.12.002

Bilbo, S. D., and Schwarz, J. M. (2009). Early-life programming of later-life brain and behavior: a critical role for the immune system. Front. Behav. Neurosci. 3:9. doi: $10.3389 /$ neuro.08.014.2009

Bilbo, S. D., and Tsang, V. (2010). Enduring consequences of maternal obesity for brain inflammation and behavior of offspring. FASEB J. 24, 2104-2115. doi 10.1096/fj.09-144014

Blaise, S. A., Nédélec, E., Schroeder, H., Alberto, J.-M., Bossenmeyer-Pourié, C., Guéant, J.-L., etal. (2007). Gestational vitamin B deficiency leads to homocysteine-associated brain apoptosis and alters neurobehavioral development in rats. Am. J. Pathol. 170, 667-679. doi: 10.2353/ajpath.2007. 060339

Bland, S. T., Beckley, J. T., Watkins, L. R., Maier, S. F., and Bilbo, S. D. (2010a). Neonatal Escherichia coli infection alters glial, cytokine, and neuronal gene expression in response to acute amphetamine in adolescent rats. Neurosci. Lett. 474, 52-57. doi: 10.1016/j.neulet.2010.03.006

Bland, S. T., Beckley, J. T., Young, S., Tsang, V., Watkins, L. R., Maier, S. F., et al. (2010b). Enduring consequences of early-life infection on glial and neural cell genesis within cognitive regions of the brain. Brain Behav. Immun. 24, 329-338. doi: 10.1016/j.bbi.2009.09.012

Bredy, T. W., Grant, R. J., and Champagne, D. L. (2003). Maternal care influences neuronal survival in the hippocampus of the rat. Eur. J. Neurosci. 18, 2903-2909. doi: 10.1046/j.1460-9568.2003.02965.x

Brown, A. S. (2006). Prenatal infection as a risk factor for schizophrenia. Schizophr. Bull. 32, 200-202. doi: 10.1093/schbul/sbj052

Brown, A. S., van Os, J., Driessens, C., Hoek, H. W., and Susser, E. S. (2000). Further evidence of relation between prenatal famine and major affective disorder. Am. J. Psychiatry 157, 190-195. doi: 10.1176/appi.ajp.157.2.190

Brown, C. P., Smotherman, W. P., and Levine, S. (1977). Interaction-induced reduction in differential maternal responsiveness: an effect of cue-reduction or behavior? Dev. Psychobiol. 10, 273-280. doi: 10.1002/dev.420100311

Brunson, K. L. (2005). Mechanisms of late-onset cognitive decline after earlylife stress. J. Neurosci. 25, 9328-9338. doi: 10.1523/JNEUROSCI.228105.2005

Brunson, K. L., Baram, T. Z., and Bender, R. A. (2005). Hippocampal neurogenesis is not enhanced by lifelong reduction of glucocorticoid levels. Hippocampus 15 , 491-501. doi: 10.1002/hipo.20074

Burdge, G. C., Lillycrop, K. A., Phillips, E. S., Slater-Jefferies, J. L., Jackson, A. A., and Hanson, M. A. (2009). Folic acid supplementation during the juvenile-pubertal period in rats modifies the phenotype and epigenotype induced by prenatal nutrition. J. Nutr. 139, 1054-1060. doi: 10.3945/jn.109.104653

Calon, F., and Cole, G. (2007). Neuroprotective action of omega-3 polyunsaturated fatty acids against neurodegenerative diseases: evidence from animal studies. Prostaglandins Leukot. Essent. Fatty Acids 77, 287-293. doi: 10.1016/j.plefa.2007.10.019

Cameron, H. A., and Gould, E. (1994). Adult neurogenesis is regulated by adrenal steroids in the dentate gyrus. Neuroscience 61, 203-209. doi: 10.1016/03064522(94)90224-0

Campbell, L. F., and Bedi, K. S. (1989). The effects of undernutrition during early life on spatial learning. Physiol. Behav. 45, 883-890. doi: 10.1016/00319384(89)90210-2

Canani, R. B., Costanzo, M. D., Leone, L., Bedogni, G., Brambilla, P., Cianfarani, S., et al. (2011). Epigenetic mechanisms elicited by nutrition in early life. Nutr. Res. Rev. 24, 198-205. doi: 10.1017/S0954422411000102
Capuron, L., and Miller, A. H. (2011). Immune system to brain signaling: neuropsychopharmacological implications. Pharmacol. Ther. 130, 226-238. doi: 10.1016/j.pharmthera.2011.01.014

Carpenter, L. L., Gawuga, C. E., Tyrka, A. R., Lee, J. K., Anderson, G. M., and Price, L. H. (2010). Association between plasma IL-6 response to acute stress and early-life adversity in healthy adults. Neuropsychopharmacology 35, 2617-2623. doi: 10.1038/npp.2010.159

Carrié, I., Guesnet, P., Bourre, J. M., and Francès, H. (2000). Diets containing long-chain n-3 polyunsaturated fatty acids affect behaviour differently during development than ageing in mice. Br. J. Nutr. 83, 439-447. doi: $10.1017 /$ S0007114500000544

Cartier, L., Hartley, O., Dubois-Dauphin, M., and Krause, K.-H. (2005). Chemokine receptors in the central nervous system: role in brain inflammation and neurodegenerative diseases. Brain Res. Brain Res. Rev. 48, 16-42. doi: 10.1016/j.brainresrev.2004.07.021

Castro, C. A., Tracy, M., and Rudy, J. W. (1989). Early-life undernutrition impairs the development of the learning and short-term memory processes mediating performance in a conditional-spatial discrimination task. Behav. Brain Res. 32, 255-264. doi: 10.1016/S0166-4328(89)80058-0

Chaboub, L. S., and Deneen, B. (2013). Astrocyte form and function in the developing central nervous system. Semin. Pediatr. Neurol. 20, 230-235. doi: 10.1016/j.spen.2013.10.003

Champagne, D. L., Bagot, R. C., van Hasselt, F., Ramakers, G., Meaney, M. J., de Kloet, E. R., et al. (2008). Maternal care and hippocampal plasticity: evidence for experience-dependent structural plasticity, altered synaptic functioning, and differential responsiveness to glucocorticoids and stress. J. Neurosci. 28, 60376045. doi: 10.1523/JNEUROSCI.0526-08.2008

Chaplin, D. D. (2003). 1. Overview of the immune response. J. Allergy Clin. Immunol. 111, S442-S459. doi: 10.1067/mai.2003.125

Chaplin, D. D. (2010). Overview of the immune response. J. Allergy Clin. Immunol. 125, S3-S23. doi: 10.1016/j.jaci.2009.12.980

Chen, E., Miller, G. E., Kobor, M. S., and Cole, S. W. (2010). Maternal warmth buffers the effects of low early-life socioeconomic status on pro-inflammatory signaling in adulthood. Mol. Psychiatry 16, 729-737. doi: 10.1038/mp.2010.53

Chen, J., Evans, A. N., Liu, Y., Honda, M., Saavedra, J. M., and Aguilera, G. (2012). Maternal deprivation in rats is associated with corticotrophin-releasing hormone $(\mathrm{CRH})$ promoter hypomethylation and enhances $\mathrm{CRH}$ transcriptional responses to stress in adulthood. J. Neuroendocrinol. 24, 1055-1064. doi: 10.1111/j.13652826.2012.02306.x

Chugani, H. T., Behen, M. E., Muzik, O., Juhász, C., Nagy, F., and Chugani, D. C. (2001). Local brain functional activity following early deprivation: a study of postinstitutionalized Romanian orphans. Neuroimage 14, 1290-1301. doi: 10.1006/nimg.2001.0917

Cignacco, E., Hamers, J. P. H., Stoffel, L., van Lingen, R. A., Gessler, P., McDougall, J., et al. (2007). The efficacy of non-pharmacological interventions in the management of procedural pain in preterm and term neonates. A systematic literature review. Eur. J. Pain 11, 139-152. doi: 10.1016/j.ejpain.2006.02.010

Coelho, R., Viola, T. W., Walss-Bass, C., Brietzke, E., and Grassi-Oliveira, R. (2014). Childhood maltreatment and inflammatory markers: a systematic review. Acta Psychiatr. Scand. 129, 180-192. doi: 10.1111/acps.12217

Cope, E. C., and Gould, E. (2013). Cytokines make an indelible impression on neural stem cells. Cell Stem Cell 13, 507-508. doi: 10.1016/j.stem.2013.10.011

Costello, E. J., Worthman, C., Erkanli, A., and Angold, A. (2007). Prediction from low birth weight to female adolescent depression: a test of competing hypotheses. Arch. Gen. Psychiatry 64, 338-344. doi: 10.1001/archpsyc.64.3.338

Coupé, B., Dutriez-Casteloot, I., Breton, C., Lefèvre, F., Mairesse, J., DickesCoopman, A., et al. (2009). Perinatal undernutrition modifies cell proliferation and brain-derived neurotrophic factor levels during critical time-windows for hypothalamic and hippocampal development in the male rat. J. Neuroendocrinol. 21, 40-48. doi: 10.1111/j.1365-2826.2008.01806.x

Craciunescu, C. N., Johnson, A. R., and Zeisel, S. H. (2010). Dietary choline reverses some, but not all, effects of folate deficiency on neurogenesis and apoptosis in fetal mouse brain. J. Nutr. 140, 1162-1166. doi: 10.3945/jn.110.122044

Cunningham, C. L., Martínez-Cerdeño, V., and Noctor, S. C. (2013). Microglia regulate the number of neural precursor cells in the developing cerebral cortex. J. Neurosci. 33, 4216-4233. doi: 10.1523/JNEUROSCI.3441-12.2013

Dammann, O., Kuban, K. C. K., and Leviton, A. (2002). Perinatal infection, fetal inflammatory response, white matter damage, and cognitive limitations 
in children born preterm. Ment. Retard. Dev. Disabil. Res. Rev. 8, 46-50. doi: 10.1002/mrdd.10005

Danese, A., Moffitt, T. E., Harrington, H., Milne, B. J., Polanczyk, G., Pariante, C. M., et al. (2009). Adverse childhood experiences and adult risk factors for age-related disease: depression, inflammation, and clustering of metabolic risk markers. Arch. Pediatr. Adolesc. Med. 163, 1135-1143. doi: 10.1001/archpediatrics. 2009.214

Dangat, K. D., Mehendale, S. S., Yadav, H. R., Kilari, A. S., Kulkarni, A. V., Taralekar, V. S., et al. (2010). Long-chain polyunsaturated fatty acid composition of breast milk in pre-eclamptic mothers. Neonatology 97, 190-194. doi: 10.1159/ 000252971

Das, S., and Basu, A. (2008). Inflammation: a new candidate in modulating adult neurogenesis. J. Neurosci. Res. 86, 1199-1208. doi: 10.1002/jnr.21585

Das, S., and Basu, A. (2011). Viral infection and neural stem/progenitor cell's fate: implications in brain development and neurological disorders. Neurochem. Int 59, 357-366. doi: 10.1016/j.neuint.2011.02.020

de Groot, R. H., Stein, A. D., Jolles, J., van Boxtel, M. P., Blauw, G.-J., van de Bor, M., et al. (2011). Prenatal famine exposure and cognition at age 59 years. Int. J. Epidemiol. 40, 327-337. doi: 10.1093/ije/dyq261

de Kloet, E. R., Claessens, S. E. F., and Kentrop, J. (2014). Context modulates outcome of perinatal glucocorticoid action in the brain. Front. Endocrinol. (Lausanne) 5:100. doi: 10.3389/fendo.2014.00100

de Rooij, S. R., Wouters, H., Yonker, J. E., Painter, R. C., and Roseboom, T. J. (2010). Prenatal undernutrition and cognitive function in late adulthood. Proc. Natl. Acad. Sci. U.S.A. 107, 16881-16886. doi: 10.1073/pnas.1009459107

Desai, M., Gayle, D. A., Casillas, E., Boles, J., and Ross, M. G. (2009). Early undernutrition attenuates the inflammatory response in adult rat offspring. J. Matern. Fetal Neonatal Med. 22, 571-575. doi: 10.1080/14767050902874105

de Souza, A. S., Fernandes, F. S., and do Carmo, M. D. G. T. (2011). Effects of maternal malnutrition and postnatal nutritional rehabilitation on brain fatty acids, learning, and memory. Nutr. Rev. 69, 132-144. doi: 10.1111/j.17534887.2011.00374.x

Dimatelis, J. J., Pillay, N. S., Mutyaba, A. K., Russell, V. A., Daniels, W. M. U., and Stein, D. J. (2012). Early maternal separation leads to down-regulation of cytokine gene expression. Metab. Brain Dis. 27, 393-397. doi: 10.1007/s11011-012-9304-Z

Dinel, A., Joffre, C., Trifilieff, P., Aubert, A., Foury, A., Le Ruyet, P., et al. (2014). Inflammation early in life is a vulnerability factor for emotional behavior at adolescence and for lipopolysaccharide-induced spatial memory and neurogenesis alteration at adulthood. J. Neuroinflammation 11:155. doi: 10.1186/s12974-014-0155-x

Diz-Chaves, Y. (2011). Ghrelin, appetite regulation, and food reward: interaction with chronic stress. Int. J. Pept. 2011:898450. doi: 10.1155/2011/898450

Diz-Chaves, Y., Astiz, M., Bellini, M. J., and Garcia-Segura, L. M. (2013). Prenatal stress increases the expression of proinflammatory cytokines and exacerbates the inflammatory response to LPS in the hippocampal formation of adult male mice. Brain Behav. Immun. 28, 196-206. doi: 10.1016/j.bbi.2012.11.013

Diz-Chaves, Y., Pernía, O., Carrero, P., and Garcia-Segura, L. M. (2012). Prenatal stress causes alterations in the morphology of microglia and the inflammatory response of the hippocampus of adult female mice. J. Neuroinflammation 9:71. doi: 10.1186/1742-2094-9-71

Doosti, M.-H., Bakhtiari, A., Zare, P., Amani, M., Majidi-Zolbanin, N., Babri, S., et al. (2013). Impacts of early intervention with fluoxetine following early neonatal immune activation on depression-like behaviors and body weight in mice. Prog. Neuropsychopharmacol. Biol. Psychiatry 43, 55-65. doi: 10.1016/j.pnpbp.2012.12.003

Dranovsky, A., and Hen, R. (2006). Hippocampal neurogenesis: regulation by stress and antidepressants. Biol. Psychiatry 59, 1136-1143. doi: 10.1016/j.biopsych.2006.03.082

Ekdahl, C. T. (2012). Microglial activation - tuning and pruning adult neurogenesis. Front. Pharmacol. 3:41. doi: 10.3389/fphar.2012.00041

Ekdahl, C. T., Kokaia, Z., and Lindvall, O. (2009). Brain inflammation and adult neurogenesis: the dual role of microglia. Neuroscience 158, 1021-1029. doi: 10.1016/j.neuroscience.2008.06.052

Engelhardt, B. (2003). Development of the blood-brain barrier. Cell Tissue Res. 314 119-129. doi: 10.1007/s00441-003-0751-z

Eriksen, W., Sundet, J. M., and Tambs, K. (2009). Register data suggest lower intelligence in men born the year after flu pandemic. Ann. Neurol. 66, 284-289. doi: 10.1002/ana.21702
Fabricius, K., Wörtwein, G., and Pakkenberg, B. (2008). The impact of maternal separation on adult mouse behaviour and on the total neuron number in the mouse hippocampus. Brain Struct. Funct. 212, 403-416. doi: 10.1007/s00429007-0169-6

Fedorova, I., Hussein, N., Baumann, M. H., Di Martino, C., and Salem, N. (2009). An n-3 fatty acid deficiency impairs rat spatial learning in the Barnes maze. Behav. Neurosci. 123, 196-205. doi: 10.1037/a0013801

Feldman, R., Singer, M., and Zagoory, O. (2010). Touch attenuates infants' physiological reactivity to stress. Dev. Sci. 13, 271-278. doi: 10.1111/j.14677687.2009.00890.x

Fenoglio, K. A., Brunson, K. L., and Baram, T. Z. (2006). Hippocampal neuroplasticity induced by early-life stress: functional and molecular aspects. Front. Neuroendocrinol. 27:180-192. doi: 10.1016/j.yfrne.2006.02.001

Fernández-Riejos, P., Najib, S., Santos-Alvarez, J., Martín-Romero, C., Pérez-Pérez, A., González-Yanes, C., et al. (2010). Role of leptin in the activation of immune cells. Mediators Inflamm. 2010:568343. doi: 10.1155/2010/568343

Francis, D. D., Champagne, F. C., and Meaney, M. J. (2000). Variations in maternal behaviour are associated with differences in oxytocin receptor levels in the rat. J. Neuroendocrinol. 12, 1145-1148. doi: 10.1046/j.1365-2826.2000.00599.x

Francis, D. D., Diorio, J., Plotsky, P. M., and Meaney, M. J. (2002). Environmental enrichment reverses the effects of maternal separation on stress reactivity. J. Neurosci. 22, 7840-7843.

Francis, D. D., and Meaney, M. J. (1999). Maternal care and the development of stress responses. Curr. Opin. Neurobiol. 9, 128-134. doi: 10.1016/S09594388(99)80016-6

Fukuda, A., Fukuda, H., Swanpalmer, J., Hertzman, S., Lannering, B., Marky, I., et al. (2005). Age-dependent sensitivity of the developing brain to irradiation is correlated with the number and vulnerability of progenitor cells. J. Neurochem. 92, 569-584. doi: 10.1111/j.1471-4159.2004.02894.x

Galic, M. A., Riazi, K., Henderson, A. K., Tsutsui, S., and Pittman, Q. J. (2009). Virallike brain inflammation during development causes increased seizure susceptibility in adult rats. Neurobiol. Dis. 36, 343-351. doi: 10.1016/j.nbd.2009.07.025

Garden, G. A. (2013). Epigenetics and the modulation of neuroinflammation. Neurotherapeutics 10, 782-788. doi: 10.1007/s13311-013-0207-4

Gebara, E., Sultan, S., Kocher-Braissant, J., and Toni, N. (2013). Adult hippocampal neurogenesis inversely correlates with microglia in conditions of voluntary running and aging. Front. Neurosci. 7:145. doi: 10.3389/fnins.2013.00145

Gómez-González, B., and Escobar, A. (2009a). Altered functional development of the blood-brain barrier after early life stress in the rat. Brain Res. Bull. 79, 376-387. doi: 10.1016/j.brainresbull.2009.05.012

Gómez-González, B., and Escobar, A. (2009b). Prenatal stress alters microglial development and distribution in postnatal rat brain. Acta Neuropathol. 119, 303-315. doi: 10.1007/s00401-009-0590-4

Gould, E., Tanapat, P., Rydel, T., and Hastings, N. (2000). Regulation of hippocampal neurogenesis in adulthood. Biol. Psychiatry 48, 715-720. doi: 10.1016/S00063223(00)01021-0

Green, H. F., and Nolan, Y. M. (2014). Inflammation and the developing brain: consequences for hippocampal neurogenesis and behavior. Neurosci. Biobehav. Rev. 40, 1-15. doi: 10.1016/j.neubiorev.2014.01.004

Greter, M., and Merad, M. (2013). Regulation of microglia development and homeostasis. Glia 61, 121-127. doi: 10.1002/glia.22408

Halassa, M. M., Florian, C., Fellin, T., Munoz, J. R., Lee, S.-Y., Abel, T., et al. (2009). Astrocytic modulation of sleep homeostasis and cognitive consequences of sleep loss. Neuron 61, 213-219. doi: 10.1016/j.neuron.2008.11.024

Harré, E. M., Galic, M. A., Mouihate, A., Noorbakhsh, F., and Pittman, Q. J. (2008). Neonatal inflammation produces selective behavioural deficits and alters $\mathrm{N}$-methyl-d-aspartate receptor subunit mRNA in the adult rat brain. Eur. J. Neurosci. 27, 644-653. doi: 10.1111/j.1460-9568.2008.06031.x

Hedges, D. W., and Woon, F. L. (2011). Early-life stress and cognitive outcome. Psychopharmacology (Berl.) 214, 121-130. doi: 10.1007/s00213-010-2090-6

Heijmans, B. T., Tobi, E. W., Stein, A. D., Putter, H., Blauw, G. J., Susser, E. S., et al. (2008). Persistent epigenetic differences associated with prenatal exposure to famine in humans. Proc. Natl. Acad. Sci. U.S.A. 105, 17046-17049. doi: 10.1073/pnas.0806560105

Heim, C., and Binder, E. B. (2012). Current research trends in early life stress and depression: review of human studies on sensitive periods, geneenvironment interactions, and epigenetics. Exp. Neurol. 233, 102-111. doi: 10.1016/j.expneurol.2011.10.032 
Hulshof, H. J., Novati, A., Sgoifo, A., Luiten, P. G., den, Boer, J. A., and Meerlo, P. (2011). Maternal separation decreases adult hippocampal cell proliferation and impairs cognitive performance but has little effect on stress sensitivity and anxiety in adult Wistar rats. Behav. Brain Res. 216, 552-560. doi: 10.1016/j.bbr.2010.08.038

Huot, R. L., Plotsky, P. M., Lenox, R. H., and McNamara, R. K. (2002). Neonatal maternal separation reduces hippocampal mossy fiber density in adult Long Evans rats. Brain Res. 950, 52-63. doi: 10.1016/S0006-8993(02)02985-2

Innis, S. M. (2008). Dietary omega 3 fatty acids and the developing brain. Brain Res. 1237, 35-43. doi: 10.1016/j.brainres.2008.08.078

Ivy, A. S., Brunson, K. L., Sandman, C., and Baram, T. Z. (2008). Dysfunctional nurturing behavior in rat dams with limited access to nesting material: a clinically relevant model for early-life stress. Neuroscience 154, 1132-1142. doi: 10.1016/j.neuroscience.2008.04.019

Ivy, A. S., Rex, C. S., Chen, Y., Dubé, C., Maras, P. M., Grigoriadis, D. E., et al. (2010). Hippocampal dysfunction and cognitive impairments provoked by chronic earlylife stress involve excessive activation of CRH receptors. J. Neurosci. 30, 1300513015. doi: 10.1523/JNEUROSCI.1784-10.2010

Iwasa, T., Matsuzaki, T., Kinouchi, R., Fujisawa, S., Murakami, M., Kiyokawa, M. et al. (2010). Neonatal LPS injection alters the body weight regulation systems of rats under non-stress and immune stress conditions. Int. J. Dev. Neurosci. 28, 119-124. doi: 10.1016/j.ijdevneu.2009.08.015

Järlestedt, K., Naylor, A. S., Dean, J., Hagberg, H., and Mallard, C. (2013). Decreased survival of newborn neurons in the dorsal hippocampus after neonatal LPS exposure in mice. Neuroscience 253,21-28. doi: 10.1016/j.neuroscience.2013.08.040

Kamphuis, P., Gardoni, F., Kamal, A., Croiset, G., Bakker, J. M., Cattabeni, F., et al. (2003). Long-lasting effects of neonatal dexamethasone treatment on spatial learning and hippocampal synaptic plasticity. Involvement of the NMDA receptor complex. FASEB J. 17, 911-913. doi: 10.1096/fj.02-0333fje

Kaplan, G. A., Turrell, G., Lynch, J. W., Everson, S. A., Helkala, E. L., and Salonen, J. T. (2001). Childhood socioeconomic position and cognitive function in adulthood. Int. J. Epidemiol. 30, 256-263. doi: 10.1093/ije/30.2.256

Katz, H. B., Davies, C. A., and Dobbing, J. (1982). Effects of undernutrition at different ages early in Llife and later environmental complexity on parameters of the cerebrum and hippocampus in rats. J. Nutr. 112, 1362-1368.

Kelly, D., and Coutts, A. G. P. (2000). Early nutrition and the development of immune function in the neonate. Proc. Nutr. Soc. 59, 177-185. doi: $10.1017 / \mathrm{S} 0029665100000197$

Kempermann, G., Jessberger, S., Steiner, B., and Kronenberg, G. (2004). Milestones of neuronal development in the adult hippocampus. Trends Neurosci. 27, 447-452. doi: 10.1016/j.tins.2004.05.013

Kempermann, G., Kuhn, H. G., and Gage, F. H. (1997). More hippocampal neurons in adult mice living in an enriched environment. Nature 386, 493-495. doi: $10.1038 / 386493 \mathrm{a} 0$

Kohman, R. A., and Rhodes, J. S. (2013). Neurogenesis, inflammation and behavior Brain Behav. Immun. 27, 22-32. doi: 10.1016/j.bbi.2012.09.003

Kohman, R. A., Tarr, A. J., Day, C. E., McLinden, K. A., and Boehm, G. W. (2008) Influence of prenatal stress on behavioral, endocrine, and cytokine responses to adulthood bacterial endotoxin exposure. Behav. Brain Res. 193, 257-268. doi: 10.1016/j.bbr.2008.06.004

Korosi, A., and Baram, T. Z. (2010). Plasticity of the stress response early in life: mechanisms and significance. Dev. Psychobiol. 52, 661-670. doi: 10.1002/dev.20490

Korosi, A., Naninck, E. F. G., Oomen, C. A., Schouten, M., Krugers, H., Fitzsimons, C., etal. (2012). Early-life stress mediated modulation of adult neurogenesis and behavior. Behav. Brain Res. 227, 400-409. doi: 10.1016/j.bbr.2011.07.037

Korosi, A., Shanabrough, M., McClelland, S., Liu, Z.-W., Borok, E., Gao, X.-B., et al (2010). Early-life experience reduces excitation to stress-responsive hypothalamic neurons and reprograms the expression of corticotropin-releasing hormone. J. Neurosci. 30, 703-713. doi: 10.1523/JNEUROSCI.4214-09.2010

Kumar, G., Jones, N. C., Morris, M. J., Rees, S., O’Brien, T. J., and Salzberg, M. R. (2011). Early life stress enhancement of limbic epileptogenesis in adult rats: mechanistic insights. PLOS ONE 6:e24033. doi: 10.1371/journal.pone. 0024033

Lamptey, M. S., and Walker, B. L. (1978). Learning behavior and brain lipid composition in rats subjected to essential fatty acid deficiency during gestation, lactation and growth. J. Nutr. 108, 358-367.
Laus, M. F., Vales, L. D. M. F., Costa, T. M. B., and Almeida, S. S. (2011). Early postnatal protein-calorie malnutrition and cognition: a review of human and animal studies. Int. J. Environ. Res. Public Health 8, 590-612. doi: 10.3390/ijerph8020590

Lei, X., Zhang, W., Liu, T., Xiao, H., Liang, W., Xia, W., et al. (2013). Perinatal supplementation with omega-3 polyunsaturated fatty acids improves sevoflurane-induced neurodegeneration and memory impairment in neonatal rats. PLoS ONE 8:e70645. doi: 10.1371/journal.pone.0070645

Leventopoulos, M., Rueedi-Bettschen, D., Knuesel, I., Feldon, J., Pryce, C. R., and Opacka-Juffry, J. (2007). Long-term effects of early life deprivation on brain glia in Fischer rats. Brain Res. 1142, 119-126. doi: 10.1016/j.brainres.2007. 01.039

Levine, S., Huchton, D. M., Wiener, S. G., and Rosenfeld, P. (1991). Time course of the effect of maternal deprivation on the hypothalamic-pituitary-adrenal axis in the infant rat. Dev. Psychobiol. 24, 547-558. doi: 10.1002/dev.420240803

Libbey, J., Sweeten, T., McMahon, W., and Fujinami, R. (2005). Autistic disorder and viral infections. J. Neurovirol. 11, 1-10. doi: 10.1080/13550280590900553

Lim, S.-Y., Hoshiba, J., Moriguchi, T., and Salem, N. (2005). N-3 fatty acid deficiency induced by a modified artificial rearing method leads to poorer performance in spatial learning tasks. Pediatr. Res. 58, 741-748. doi: 10.1203/01.PDR. 0000180547.46725.CC

Lindqvist, A., Mohapel, P., Bouter, B., Frielingsdorf, H., Pizzo, D., Brundin, P., et al. (2006). High-fat diet impairs hippocampal neurogenesis in male rats. Eur. J. Neurol. 13, 1385-1388. doi: 10.1111/j.1468-1331.2006.01500.x

Liu, B., Zupan, B., Laird, E., Klein, S., Gleason, G., Bozinoski, M., et al. (2014). Maternal hematopoietic TNF, via milk chemokines, programs hippocampal development and memory. Nat. Neurosci. 17, 97-105. doi: 10.1038/nn.3596

Liu, D., Diorio, J., Tannenbaum, B., Caldji, C., Francis, D., Freedman, A., et al. (1997). Maternal care, hippocampal glucocorticoid receptors, and hypothalamicpituitary-adrenal responses to stress. Science 277, 1659-1662. doi: 10.1126/ science.277.5332.1659

Llorente, R., Arranz, L., Marco, E.-M., Moreno, E., Puerto, M., Guaza, C., et al. (2007). Early maternal deprivation and neonatal single administration with a cannabinoid agonist induce long-term sex-dependent psychoimmunoendocrine effects in adolescent rats. Psychoneuroendocrinology 32, 636-650. doi: 10.1016/j.psyneuen.2007.04.002

Loi, M., Koricka, S., Lucassen, P. J., and Joëls, M. (2014). Age- and sex-dependent effects of early life stress on hippocampal neurogenesis. Front. Endocrinol. 5:13. doi: $10.3389 /$ fendo. 2014.00013

Lucas, A. (1998). Programming by early nutrition: an experimental approach. J. Nutr. 128, 401S-406S

Lucassen, P. J., Meerlo, P., Naylor, A. S., Van Dam, A. M., Dayer, A. G., Fuchs, E., et al. (2010). Regulation of adult neurogenesis by stress, sleep disruption, exercise and inflammation: implications for depression and antidepressant action. Eur. Neuropsychopharmacol. 20, 1-17. doi: 10.1016/j.euroneuro.2009.08.003

Lucassen, P. J., Naninck, E. F. G., van Goudoever, J. B., Fitzsimons, C., Joëls, M., and Korosi, A. (2013). Perinatal programming of adult hippocampal structure and function; emerging roles of stress, nutrition and epigenetics. Trends Neurosci. 36, 621-631. doi: 10.1016/j.tins.2013.08.002

Macrì, S., Mason, G. J., and Wurbel, H. (2004). Dissociation in the effects of neonatal maternal separations on maternal care and the offspring's HPA and fear responses in rats. Eur. J. Neurosci. 20, 1017-1024. doi: 10.1111/j.1460-9568.2004.03541.x

Madore, C., Nadjar, A., Delpech, J.-C., Sere, A., Aubert, A., Portal, C., et al. (2014). Nutritional n-3 PUFAs deficiency during perinatal periods alters brain innate immune system and neuronal plasticity-associated genes. Brain Behav. Immun. 41, 22-31. doi: 10.1016/j.bbi.2014.03.021

Marques, A. H., O’Connor, T. G., Roth, C., Susser, E., and Biørke-Monsen, A.-L. (2013). The influence of maternal prenatal and early childhood nutrition and maternal prenatal stress on offspring immune system development and neurodevelopmental disorders. Front. Neurosci. 7:120. doi: 10.3389/fnins.2013.00120

Martinez, Y., Diaz-Cintra, S., Leon-Jacinto, U., Aguilar-Vazquez, A., Medina, A. C., Quirarte, G. L., et al. (2009). Effects of postnatal malnutrition and senescence on learning, long-term memory, and extinction in the rat. Behav. Brain Res. 203, 48-53. doi: 10.1016/j.bbr.2009.04.016

Maselko, J., Kubzansky, L., Lipsitt, L., and Buka, S. L. (2011). Mother's affection at 8 months predicts emotional distress in adulthood. J. Epidemiol. Community Health 65, 621-625. doi: 10.1136/jech.2009.097873

Matos, R., Orozco-Solis, R., and de Souza, S. L. (2011). Nutrient restriction during early life reduces cell proliferation in the hippocampus at adulthood but 
does not impair the neuronal differentiation process of the new generated cells. Neuroscience 196, 16-24. doi: 10.1016/j.neuroscience.2011.08.071

McMillen, I. C., MacLaughlin, S. M., Muhlhausler, B. S., Gentili, S., Duffield, J. L., and Morrison, J. L. (2008). Developmental origins of adult health and disease: the role of periconceptional and foetal nutrition. Basic Clin. Pharmacol. Toxicol. 102, 82-89. doi: 10.1111/j.1742-7843.2007.00188.x

McNamara, R. K., and Carlson, S. E. (2006). Role of omega-3 fatty acids in brain development and function: potential implications for the pathogenesis and prevention of psychopathology. Prostaglandins Leukot. Essent. Fatty Acids 75, 329-349. doi: 10.1016/j.plefa.2006.07.010

Meck, W. H., and Williams, C. L. (1999). Choline supplementation during prenatal development reduces proactive interference in spatial memory. Dev. Brain Res. 118, 51-59. doi: 10.1016/S0165-3806(99)00105-4

Mela, V., Llorente-Berzal, Á., Díaz, F., Argente, J., Viveros, M.-P., and Chowen, J. A. (2012). Maternal deprivation exacerbates the response to a high fat diet in a sexually dimorphic manner. PLoS ONE 7:e48915. doi: 10.1371/journal.pone.0048915

Miller, A. A., and Spencer, S. J. (2014). Obesity and neuroinflammation: a pathway to cognitive impairment. Brain Behav. Immun. 42, 10-21. doi: 10.1016/j.bbi.2014.04.001

Miller, B. J., Culpepper, N., Rapaport, M. H., and Buckley, P. (2013). Prenatal inflammation and neurodevelopment in schizophrenia: a review of human studies. Prog. Neuropsychopharmacol. Biol. Psychiatry 42, 92-100. doi: 10.1016/j.pnpbp.2012.03.010

Miller, G. E., Chen, E., Fok, A. K., Walker, H., Lim, A., Nicholls, E. F., et al. (2009). Low early-life social class leaves a biological residue manifested by decreased glucocorticoid and increased proinflammatory signaling. Proc. Natl. Acad. Sci. U.S.A. 106, 14716-14721. doi: 10.1073/pnas.0902971106

Mirescu, C., Peters, J. D., and Gould, E. (2004). Early life experience alters response of adult neurogenesis to stress. Nat. Neurosci. 7, 841-846. doi: 10.1038/ nn 1290

Monk, C., Georgieff, M. K., and Osterholm, E. A. (2013). Research review: maternal prenatal distress and poor nutrition - mutually influencing risk factors affecting infant neurocognitive development. J. Child Psychol. Psychiatry 54, 115-130. doi: 10.1111/jcpp. 12000

Morris, M. S. (2003). Homocysteine and Alzheimer's disease. Lancet Neurol. 2, 425-428. doi: 10.1016/S1474-4422(03)00438-1

Mueller, S. C., Maheu, F. S., Dozier, M., Peloso, E., Mandell, D., Leibenluft, E., et al. (2010). Early-life stress is associated with impairment in cognitive control in adolescence: an fMRI study. Neuropsychologia 48, 3037-3044. doi: 10.1016/j.neuropsychologia.2010.06.013

Murgatroyd, C., Patchev, A. V., Wu, Y., Micale, V., Bockmühl, Y., Fischer, D., et al. (2009). Dynamic DNA methylation programs persistent adverse effects of earlylife stress. Nat. Neurosci. 12, 1559-1566. doi: 10.1038/nn.2436

Musaelyan, K., Egeland, M., Fernandes, C., Pariante, C. M., Zunszain, P. A., and Thuret, S. (2014). Modulation of adult hippocampal neurogenesis by earlylife environmental challenges triggering immune activation. Neural Plast. 2014 194396. doi: 10.1155/2014/194396

Nair, A., Vadodaria, K. C., Banerjee, S. B., Benekareddy, M., Dias, B. G., Duman, R. S. et al. (2007). Stressor-specific regulation of distinct brain-derived neurotrophic factor transcripts and cyclic AMP response element-binding protein expression in the postnatal and adult rat hippocampus. Neuropsychopharmacology 32, 1504 1519. doi: 10.1038/sj.npp. 1301276

Naninck, E. F. G., Hoeijmakers, L., Kakava-Georgiadou, N., Meesters, A., Lazic, S. E., Lucassen, P. J., et al. (2014). Chronic early-life stress alters developmental and adult neurogenesis and impairs cognitive function in mice. Hippocampus. doi: 10.1002/hipo.22374 [Epub ahead of print].

Naninck, E. F. G., Lucassen, P. J., and Korosi, A. (2013). "Consequences of earlylife experiences on cognition and emotion: a role for nutrition and epigenetic mechanisms," in Molecular Psychology, ed. T. Canli (Oxford Handbooks Online). doi: 10.1093/oxfordhb/9780199753888.013.003

Navarro-Quiroga, I., Hernandez-Valdes, M., Lin, S. L., and Naegele, J. R. (2006). Postnatal cellular contributions of the hippocampus subventricular zone to the dentate gyrus, corpus callosum, fimbria, and cerebral cortex. J. Comp. Neurol. 497, 833-845. doi: 10.1002/cne.21037

Nelson, C. A., Zeanah, C. H., Fox, N. A., Marshall, P. J., Smyke, A. T., and Guthrie, D. (2007). Cognitive recovery in socially deprived young children: the Buchares early intervention project. Science 318, 1937-1940. doi: 10.1126/science. 1143921
Niculescu, M. D., Lupu, D. S., and Craciunescu, C. N. (2011). Maternal $\alpha$-linolenic acid availability during gestation and lactation alters the postnatal hippocampal development in the mouse offspring. Int. J. Dev. Neurosci. 29, 795-802. doi: 10.1016/j.ijdevneu.2011.09.006

Nilsson, M., Perfilieva, E., Johansson, U., Orwar, O., and Eriksson, P. S. (1999). Enriched environment increases neurogenesis in the adult rat dentate gyrus and improves spatial memory. J. Neurobiol. 39, 569-578. doi: 10.1002/(SICI)10974695(19990615)39:4<569::AID-NEU10>3.0.CO;2-F

O'Connor, T. G., Moynihan, J. A., and Caserta, M. T. (2014). Annual research review: the neuroinflammation hypothesis for stress and psychopathology in children-developmental psychoneuroimmunology. J. Child Psychol. Psychiatry 55, 615-631. doi: 10.1111/jcpp.12187

Oitzl, M. S., Workel, J. O., Fluttert, M., Frosch, F., and de Kloet, E. R. (2000). Maternal deprivation affects behaviour from youth to senescence: amplification of individual differences in spatial learning and memory in senescent Brown Norway rats. Eur. J. Neurosci. 12, 3771-3780. doi: 10.1046/j.1460-9568.2000.00231.x

Olah, M., Ping, G., De Haas, A. H., Brouwer, N., Meerlo, P., Van Der Zee, E. A., et al. (2009). Enhanced hippocampal neurogenesis in the absence of microglia $\mathrm{T}$ cell interaction and microglia activation in the murine running wheel model. Glia 57, 1046-1061. doi: 10.1002/glia.20828

Oomen, C. A., Girardi, C. E. N., Cahyadi, R., Verbeek, E. C., Krugers, H., Joëls, M., etal. (2009). Opposite effects of early maternal deprivation on neurogenesis in male versus female rats. PLOS ONE 4:e3675. doi: 10.1371/journal.pone. 0003675

Oomen, C. A., Soeters, H., Audureau, N., Vermunt, L., van Hasselt, F. N., Manders, E. M. M., et al. (2010). Severe early life stress hampers spatial learning and neurogenesis, but improves hippocampal synaptic plasticity and emotional learning under high-stress conditions in adulthood. J. Neurosci. 30, 6635-6645. doi: 10.1523/JNEUROSCI.0247-10.2010

Oomen, C. A., Soeters, H., Audureau, N., Vermunt, L., van Hasselt, F. N., Manders, E. M. M., et al. (2011). Early maternal deprivation affects dentate gyrus structure and emotional learning in adult female rats. Psychopharmacology (Berl.) 214, 249-260. doi: 10.1007/s00213-010-1922-8

Orr, A. G., Sharma, A., Binder, N. B., Miller, A. H., and Pearce, B. D. (2010). Interleukin-1 mediates long-term hippocampal dentate granule cell loss following postnatal viral infection. J. Mol. Neurosci. 41, 89-96. doi: 10.1007/s12031-0099293-5

Ortega, A., Jadeja, V., and Zhou, H. (2011). Postnatal development of lipopolysaccharide-induced inflammatory response in the brain. Inflamm. Res. 60, 175-185. doi: 10.1007/s00011-010-0252-y

Palacio, A., Lopez, M., Perez-Bravo, F., Monkeberg, F., and Schlesinger, L. (2002). Leptin levels are associated with immune response in malnourished infants. J. Clin. Endocrinol. Metab. 87, 3040-3046. doi: 10.1210/jcem.87.7.8636

Palmer, A. C. (2011). Nutritionally mediated programming of the developing immune system. Adv. Nutr. 2, 377-395. doi: 10.3945/an.111.000570

Pan, W., and Kastin, A. J. (1999). Penetration of neurotrophins and cytokines across the blood-brain/blood-spinal cord barrier. Adv. Drug Deliv. Rev. 36, 291-298. doi: 10.1016/S0169-409X(98)00086-6

Parpura, V., Heneka, M. T., Montana, V., Oliet, S. H. R., Schousboe, A., Haydon, P. G., et al. (2012). Glial cells in (patho)physiology. J. Neurochem. 121, 4-27. doi: 10.1111/j.1471-4159.2012.07664.x

Parylak, S. L., Deng, W., and Gage, F. H. (2014). Mother's milk programs offspring's cognition. Nat. Neurosci. 17, 8-9. doi: 10.1038/nn.3611

Pearce, B. D., Steffensen, S. C., Paoletti, A. D., Henriksen, S. J., and Buchmeier, M. J. (1996). Persistent dentate granule cell hyperexcitability after neonatal infection with lymphocytic choriomeningitis virus. J. Neurosci. 16, 220-228.

Pleasure, S. J., Collins, A. E., and Lowenstein, D. H. (2000). Unique expression patterns of cell fate molecules delineate sequential stages of dentate gyrus development. J. Neurosci. 20, 6095-6105.

Plotsky, P. M., and Meaney, M. J. (1993). Early, postnatal experience alters hypothalamic corticotropin-releasing factor (CRF) mRNA, median eminence CRF content and stress-induced release in adult rats. Mol. Brain Res. 18, 195-200. doi: 10.1016/0169-328X(93)90189-V

Prado, E. L., and Dewey, K. G. (2014). Nutrition and brain development in early life. Nutr. Rev. 72, 267-284. doi: 10.1111/nure.12102

Pryce, C. R., Bettschen, D., and Feldon, J. (2001). Comparison of the effects of early handling and early deprivation on maternal care in the rat. Dev. Psychobiol. 38, 239-251. doi: 10.1002/dev.1018 
Rantakallio, P., Jones, P., Moring, J., and Von Wendt, L. (1997). Association between central nervous system infections during childhood and adult onset schizophrenia and other psychoses: a 28-year follow-up. Int. J. Epidemiol. 26, 837-843. doi: 10.1093/ije/26.4.837

Rice, C. J., Sandman, C. A., Lenjavi, M. R., and Baram, T. Z. (2008). A novel mouse model for acute and long-lasting consequences of early life stress. Endocrinology 149, 4892-4900. doi: 10.1210/en.2008-0633

Roy, S., Kale, A., Dangat, K., Sable, P., Kulkarni, A., and Joshi, S. (2012). Maternal micronutrients (folic acid and vitamin $\mathrm{B}(12)$ ) and omega 3 fatty acids: implications for neurodevelopmental risk in the rat offspring. Brain Dev. 34, 64-71. doi: 10.1016/j.braindev.2011.01.002

Sauder, C., Wolfer, D. P., Lipp, H. P., Staeheli, P., and Hausmann, J. (2001). Learning deficits in mice with persistent Borna disease virus infection of the CNS associated with elevated chemokine expression. Behav. Brain Res. 120, 189-201. doi: 10.1016/S0166-4328(00)00370-3

Schmidt, M., Enthoven, L., Van Woezik, J. H. G., Levine, S., de Kloet, E. R., and Oitzl, M. S. (2004). The Dynamics of the hypothalamic-pituitary-adrenal axis during maternal deprivation. J. Neuroendocrinol. 16, 52-57. doi: 10.1111/j.13652826.2004.01123.x

Schmidt, M. V., Wang, X.-D., and Meijer, O. C. (2010). Early life stress paradigms in rodents: potential animal models of depression? Psychopharmacology 214, 131140. doi: 10.1007/s00213-010-2096-0

Schoderboeck, L., Adzemovic, M., Nicolussi, E.-M., Crupinschi, C., Hochmeister, S., Fischer, M.-T., et al. (2009). The "window of susceptibility" for inflammation in the immature central nervous system is characterized by a leaky blood-brain barrier and the local expression of inflammatory chemokines. Neurobiol. Dis. 35, 368-375. doi: 10.1016/j.nbd.2009.05.026

Scholl, T. O., Hediger, M. L., Schall, J. I., Khoo, C. S., and Fischer, R. L. (1996) Dietary and serum folate: their influence on the outcome of pregnancy. Am. J. Clin. Nutr. 63, 520-525.

Schwarz, J. M., and Bilbo, S. D. (2012). Sex, glia, and development: interactions in health and disease. Horm. Behav. 62, 243-253. doi: 10.1016/j.yhbeh.2012. 02.018

Schwarz, J. M., Sholar, P. W., and Bilbo, S. D. (2012). Sex differences in microglial colonization of the developing rat brain. J. Neurochem. 120, 948-963. doi 10.1111/j.1471-4159.2011.07630.x

Seckl, J. R., and Meaney, M. J. (2006). Glucocorticoid "programming” and PTSD risk. Ann. N. Y. Acad. Sci. 1071, 351-378. doi: 10.1196/annals.1364.027

Shanks, N., and Lightman, S. L. (2001). The maternal-neonatal neuro-immune interface: are there long-term implications for inflammatory or stress-related disease? J. Clin. Invest. 108, 1567-1573. doi: 10.1172/JCI14592

Sharma, A., Valadi, N., Miller, A. H., and Pearce, B. D. (2002). Neonatal viral infection decreases neuronal progenitors and impairs adult neurogenesis in the hippocampus. Neurobiol. Dis. 11, 246-256. doi: 10.1006/nbdi.2002.0531

Sierra, A., Abiega, O., Shahraz, A., and Neumann, H. (2013). Janus-faced microglia: beneficial and detrimental consequences of microglial phagocytosis. Front. Cell. Neurosci. 7:6. doi: 10.3389/fncel.2013.00006

Sierra, A., Beccari, S., Diaz-Aparicio, I., Encinas, J. M., Comeau, S., and Tremblay, M.-E. (2014). Surveillance, phagocytosis, and inflammation: how never-resting microglia influence adult hippocampal neurogenesis. Neural Plast. 2014:610343. doi: 10.1155/2014/610343

Singer, P., Shapiro, H., Theilla, M., Anbar, R., Singer, J., and Cohen, J. (2008). Anti-inflammatory properties of omega-3 fatty acids in critical illness: nove mechanisms and an integrative perspective. Intensive Care Med. 34, 1580-1592. doi: 10.1007/s00134-008-1142-4

Slezak, M., Pfrieger, F. W., and Soltys, Z. (2006). Synaptic plasticity, astrocytes and morphological homeostasis. J. Physiol. Paris 99, 84-91. doi: 10.1016/j.jphysparis.2005.12.082

Sominsky, L., Walker, A. K., Ong, L. K., Tynan, R. J., Walker, F. R., and Hodgson, D. M. (2012). Increased microglial activation in the rat brain following neonatal exposure to a bacterial mimetic. Behav. Brain Res. 226, 351-356. doi: 10.1016/j.bbr.2011.08.038

Spencer, S. J. (2013). Perinatal nutrition programs neuroimmune function long-term: mechanisms and implications. Front. Neurosci. 7:144. doi: $10.3389 /$ fnins.2013.00144

Stanton, M. E., Gutierrez, Y. R., and Levine, S. (1988). Maternal deprivation potentiates pituitary-adrenal stress responses in infant rats. Behav. Neurosci. 102, 692-700. doi: 10.1037/0735-7044.102.5.692
Steegers-Theunissen, R. P., Obermann-Borst, S. A., Kremer, D., Lindemans, J., Siebel, C., Steegers, E. A., et al. (2009). Periconceptional maternal folic acid use of 400 $\mu \mathrm{g}$ per day is related to increased methylation of the IGF2 gene in the very young child. PLoS ONE 4:e7845. doi: 10.1371/journal.pone.0007845

Stevens, S. E., Sonuga-Barke, E. J. S., Kreppner, J. M., Beckett, C., Castle, J., Colvert, E., et al. (2008). Inattention/overactivity following early severe institutional deprivation: presentation and associations in early adolescence. J. Abnorm. Child Psychol. 36, 385-398. doi: 10.1007/s10802-007-9185-5

Suri, D., Veenit, V., Sarkar, A., Thiagarajan, D., Kumar, A., Nestler, E. J., et al. (2013). Early stress evokes age-dependent biphasic changes in hippocampal neurogenesis, BDNF expression, and cognition. Biol. Psychiatry 73, 658-666. doi: 10.1016/j.biopsych.2012.10.023

Tozuka, Y., Kumon, M., Wada, E., Onodera, M., Mochizuki, H., and Wada, K. (2010). Maternal obesity impairs hippocampal BDNF production and spatial learning performance in young mouse offspring. Neurochem. Int. 57, 235-247. doi: 10.1016/j.neuint.2010.05.015

Tozuka, Y., Wada, E., and Wada, K. (2009). Diet-induced obesity in female mice leads to peroxidized lipid accumulations and impairment of hippocampal neurogenesis during the early life of their offspring. FASEB J. 23, 1920-1934. doi: 10.1096/fj.08124784

Troen, A. M., Shea-Budgell, M., Shukitt-Hale, B., Smith, D. E., Selhub, J., and Rosenberg, I. H. (2008). B-vitamin deficiency causes hyperhomocysteinemia and vascular cognitive impairment in mice. Proc. Natl. Acad. Sci. U.S.A. 105, 1247412479. doi: 10.1073/pnas.0805350105

Tsigos, C., and Chrousos, G. P. (2002). Hypothalamic-pituitary-adrenal axis, neuroendocrine factors and stress. J. Psychosom. Res. 53, 865-871. doi: 10.1016/S0022-3999(02)00429-4

Valadares, C. T., Fukuda, M. T. H., Francolin-Silva, A. L., Hernandes, A. S., and Almeida, S. S. (2010). Effects of postnatal protein malnutrition on learning and memory procedures. Nutr. Neurosci. 13, 274-282. doi: 10.1179/147683010X12611460764769

Valladolid-Acebes, I., Stucchi, P., Cano, V., Fernandez-Alfonso, M. S., Merino, B., GilOrtega, M., et al. (2011). High-fat diets impair spatial learning in the radial-arm maze in mice. Neurobiol. Learn. Mem. 95, 80-85. doi: 10.1016/j.nlm.2010.11.007

Van Dam, A. M., Brouns, M., Louisse, S., and Berkenbosch, F. (1992). Appearance of interleukin-1 in macrophages and in ramified microglia in the brain of endotoxintreated rats: a pathway for the induction of non-specific symptoms of sickness? Brain Res. 588, 291-296. doi: 10.1016/0006-8993(92)91588-6

Van Dam, F., and Van Gool, W. A. (2009). Hyperhomocysteinemia and Alzheimer's disease: a systematic review. Arch. Gerontol. Geriatr. 48, 425-430. doi: 10.1016/j.archger.2008.03.009

van der Ree, M., Tanis, J. C., Van Braeckel, K. N. J. A., Bos, A. F., and Roze, E. (2011). Functional impairments at school age of preterm born children with late-onset sepsis. Early Hum. Dev. 87, 821-826. doi: 10.1016/j.earlhumdev.2011. 06.008

van Hasselt, F. N., Cornelisse, S., Zhang, T. Y., Meaney, M. J., Velzing, E. H., Krugers, H. J., et al. (2012a). Adult hippocampal glucocorticoid receptor expression and dentate synaptic plasticity correlate with maternal care received by individuals early in life. Hippocampus 22, 255-266. doi: 10.1002/hipo.20892

van Hasselt, F. N., Tieskens, J. M., Trezza, V., Krugers, H. J., Vanderschuren, L. J. M. J., and Joels, M. (2012b). Within-litter variation in maternal care received by individual pups correlates with adolescent social play behavior in male rats. Physiol. Behav. 106, 701-706. doi: 10.1016/j.physbeh.2011.12.007

Veena, S. R., Krishnaveni, G. V., Srinivasan, K., Wills, A. K., Muthayya, S., Kurpad, A. V., et al. (2010). Higher maternal plasma folate but not vitamin B-12 concentrations during pregnancy are associated with better cognitive function scores in 9- to 10- year-old children in South India. J. Nutr. 140, 1014-1022. doi: 10.3945/jn.109.118075

Viviani, B., Boraso, M., Valero, M., Gardoni, F., Marco, E.-M., Llorente, R., et al. (2013). Early maternal deprivation immunologically primes hippocampal synapses by redistributing interleukin-1 receptor type I in a sex dependent manner. Brain Behav. Immun. 35, 135-143. doi: 10.1016/j.bbi.2013. 09.008

Walker, A. K., Nakamura, T., and Hodgson, D. M. (2010). Neonatal lipopolysaccharide exposure alters central cytokine responses to stress in adulthood in Wistar rats. Stress 13, 506-515. doi: 10.3109/10253890.2010.489977

Walker, S. P., Grantham-McGregor, S. M., Powell, C. A., and Chang, S. M. (2000). Effects of growth restriction in early childhood on growth, IQ, and cognition at age 
11 to 12 years and the benefits of nutritional supplementation and psychosocial stimulation. J. Pediatr. 137, 36-41. doi: 10.1067/mpd.2000.106227

Wang, K. C., Fan, L. W., Kaizaki, A., Pang, Y., Cai, Z., and Tien, L. T. (2013). Neonatal lipopolysaccharide exposure induces long-lasting learning impairment, less anxiety-like response and hippocampal injury in adult rats. Neuroscience 234, 146-157. doi: 10.1016/j.neuroscience.2012.12.049

Wang, X.-D., Rammes, G., Kraev, I., Wolf, M., Liebl, C., Scharf, S. H., et al. (2011). Forebrain CRF1 modulates early-life stress-programmed cognitive deficits. J. Neurosci. 31, 13625-13634. doi: 10.1523/JNEUROSCI.2259-11.2011

Weaver, I. C. G., Champagne, F. A., Brown, S. E., Dymov, S., Sharma, S., Meaney, M. J., et al. (2005). Reversal of maternal programming of stress responses in adult offspring through methyl supplementation: altering epigenetic marking later in life. J. Neurosci. 25, 11045-11054. doi: 10.1523/JNEUROSCI.3652-05.2005

Wei, L., Simen, A., Mane, S., and Kaffman, A. (2012). Early life stress inhibits expression of a novel innate immune pathway in the developing hippocampus. Neuropsychopharmacology 37, 567-580. doi: 10.1038/npp.2011.239

Williamson, L. L., Chao, A., and Bilbo, S. D. (2012). Environmental enrichment alters glial antigen expression and neuroimmune function in the adult rat hippocampus. Brain Behav. Immun. 26, 500-510. doi: 10.1016/j.bbi.2012.01.003

Williamson, L. L., Sholar, P. W., Mistry, R. S., Smith, S. H., and Bilbo, S. D. (2011). Microglia and memory: modulation by early-life infection. J. Neurosci. 31, 1551115521. doi: 10.1523/JNEUROSCI.3688-11.2011

Wolf, C., Almli, C. R., Finger, S., Ryan, S., and Morgane, P. J. (1986). Behavioral effects of severe and moderate early malnutrition. Physiol. Behav. 38, 725-730. doi: 10.1016/0031-9384(86)90270-2

Yi, S. J., and Baram, T. Z. (1994). Corticotropin-releasing hormone mediates the response to cold stress in the neonatal rat without compensatory enhancement of the peptide's gene expression. Endocrinology 135, 2364-2368. doi: 10.1210/endo.135.6.7988418

Ziko, I., De Luca, S., Dinan, T., Barwood, J. M., Sominsky, L., Cai, G., et al. (2014). Neonatal overfeeding alters hypothalamic microglial profiles and central responses to immune challenge long-term. Brain Behav. Immun. 41, 32-43. doi: 10.1016/j.bbi.2014.06.014

Zimmerberg, B., Foote, H. E., and Van Kempen, T. A. (2009). Olfactory association learning and brain-derived neurotrophic factor in an animal model of early deprivation. Dev. Psychobiol. 51, 333-344. doi: 10.1002/dev. 20373

Zocher, M., Czub, S., Schulte-Mönting, J., de la Torre, J. C., and Sander, C. (2000). Alterations in neurotrophin and neurotrophin receptor gene expression patterns in the rat central nervous system following perinatal Borna disease virus infection. J. Neurovirol. 6, 462-477. doi: 10.3109/1355028000 9091947

Zou, C.-G., Zhao, Y.-S., Gao, S.-Y., Li, S.-D., Cao, X.-Z., Zhang, M., et al. (2010). Homocysteine promotes proliferation and activation of microglia. Neurobiol. Aging 31, 2069-2079. doi: 10.1016/j.neurobiolaging.2008.11.007

Conflict of Interest Statement: The authors declare that the research was conducted in the absence of any commercial or financial relationships that could be construed as a potential conflict of interest.

Received: 28 October 2014; accepted: 16 December 2014; published online: 09 January 2015.

Citation: Hoeijmakers L, Lucassen PJ and Korosi A (2015) The interplay of early-life stress, nutrition, and immune activation programs adult hippocampal structure and function. Front. Mol. Neurosci. 7:103. doi: 10.3389/fnmol.2014.00103

This article was submitted to Frontiers in Molecular Neuroscience.

Copyright (C) 2015 Hoeijmakers, Lucassen and Korosi. This is an open-access article distributed under the terms of the Creative Commons Attribution License (CC BY).

The use, distribution or reproduction in other forums is permitted, provided the original author(s) or licensor are credited and that the original publication in this journal is cited, in accordance with accepted academic practice. No use, distribution or reproduction is permitted which does not comply with these terms. 